\title{
Assessment of the implementation and achievements of the 3D Approach in Senegal's National Family Planning Action Plan-Part 2: Summary Report
}

\author{
Fatou Mbow \\ Population Council \\ Leslie Dubent \\ Population Council \\ Nafissatou Diop \\ Population Council \\ Fatou Ndiaye Turpin \\ Bocar Mamadou Daff
}

See next page for additional authors

Follow this and additional works at: https://knowledgecommons.popcouncil.org/departments_sbsr-rh

Part of the Demography, Population, and Ecology Commons, Family, Life Course, and Society

Commons, and the International Public Health Commons

How does access to this work benefit you? Let us know!

\section{Recommended Citation}

Mbow, Fatou, Leslie Dubent, Nafissatou Diop, Fatou Ndiaye Turpin, Bocar Mamadou Daff, and Babacar Mane. 2017. "Assessment of the implementation and achievements of the 3D Approach in Senegal's National Family Planning Action Plan-Part 2: Summary Report." Dakar: Population Council, The Evidence Project. 


\section{Authors}

Fatou Mbow, Leslie Dubent, Nafissatou Diop, Fatou Ndiaye Turpin, Bocar Mamadou Daff, and Babacar Mane 


\section{Assessment of the implementation and achievements of the 3D Approach in Senegal's National Family Planning Action Plan}

\section{PART 2: SUMMARY REPORT}

Fatou Bintou Mbow, Chargée de Programmes, Population Council Leslie Dubent, Assistante de Recherche, Population Council

Nafissatou Diop, Country Director, Population Council

Fatou Ndiaye, Maternal and Child Health/Family Planning Specialist, USAID Senegal

Bocar Mamadou Daff, Directeur, Direction de la Santé de la Reproduction et de la Survie de l'Enfant. Ministère de la Santé et de l'Action Sociale du Sénégal

Babacar Mané, Chargé de Programmes, Population Council

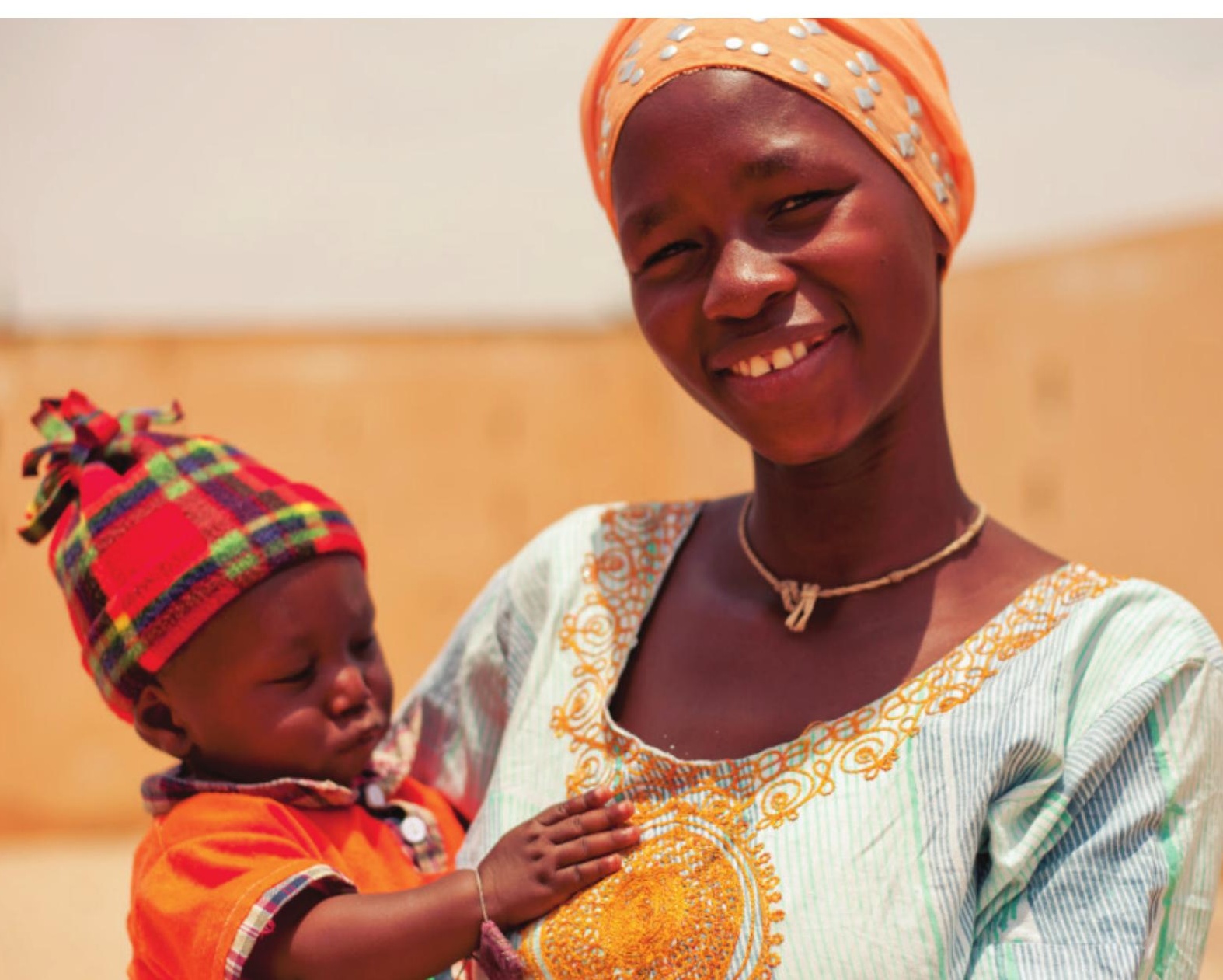


The Evidence Project

Population Council

4301 Connecticut Avenue, NW, Suite 280

Washington, DC 20008 USA

tel +12022379400

evidenceproject.popcouncil.org

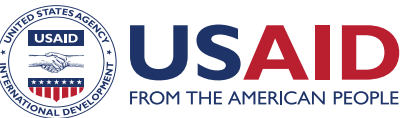

The Evidence Project is made possible by the generous support of the American people through the United States Agency for International Development (USAID) under the terms of cooperative agreement no. AID-OAA-A-13-00087.

The contents of this document are the sole responsibility of the Evidence Project and Population Council and do not necessarily reflect the views of USAID or the United States Government.

Evidence

The Evidence Project uses implementation science-the strategic generation, translation, and use of evidence-to strengthen and scale up family planning and reproductive health programs to reduce unintended pregnancies worldwide. The

Evidence Project is led by the Population Council in partnership with INDEPTH Network, International Planned Parenthood Federation, PATH, Population Reference Bureau, and a University Research Network.

Published in June 2017.

Suggested citation: Mbow FB, Dubent L, Diop N, Ndiaye F, Daff BM \& Mané B. 2017. "Assessment of the implementation and achievements of the 3D Approach within the National Family Planning Action Plan (NFPAP) in Senegal - Summary Report," Report. Dakar, Senegal: Population Council, The Evidence Project..

Photo credit on cover page: (C) 2006 Richard Nyberg, Courtesy of Photoshare.

(C) 2017 The Population Council, Inc. 


\section{Table of Contents}

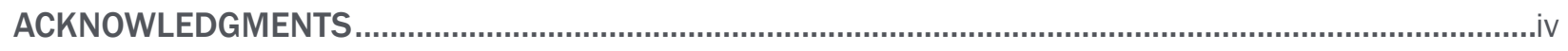

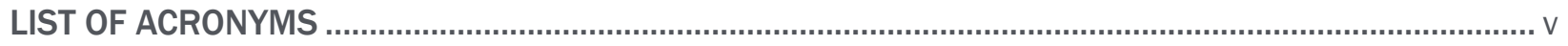

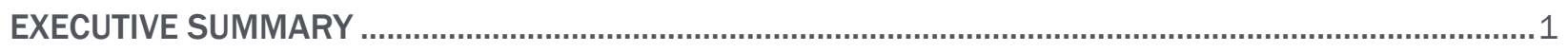

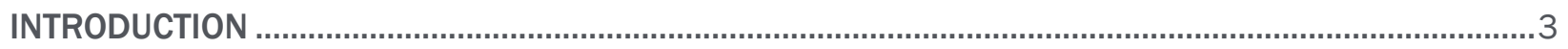

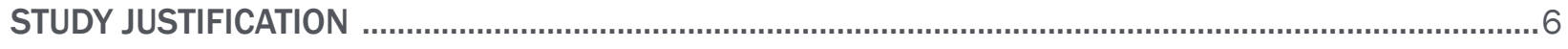

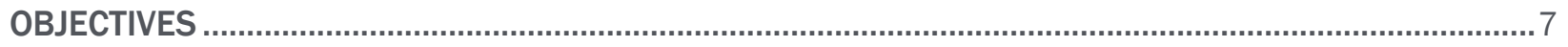

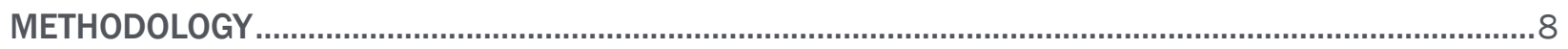

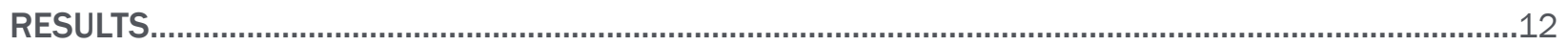

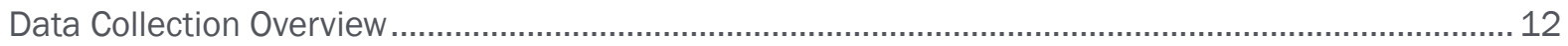

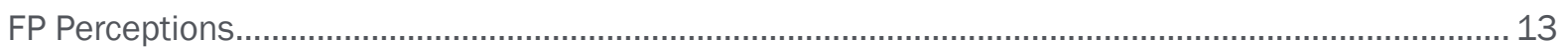

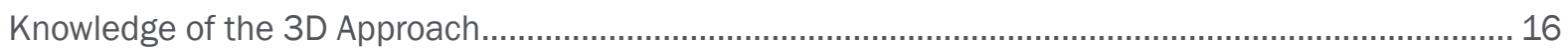

Knowledge of Action Taken Under Eache "D" of the Framework ........................................................... 16

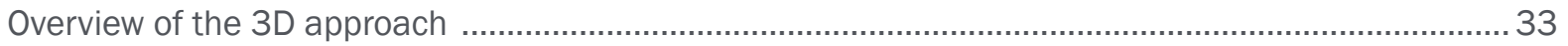

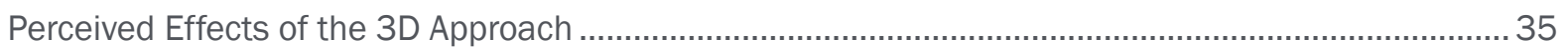

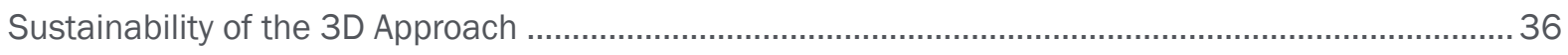

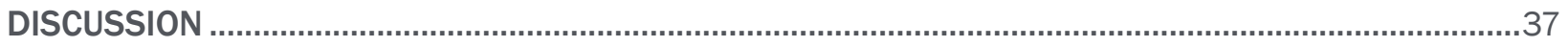

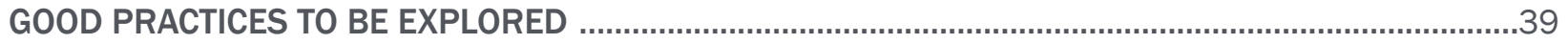

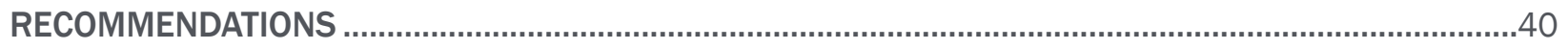

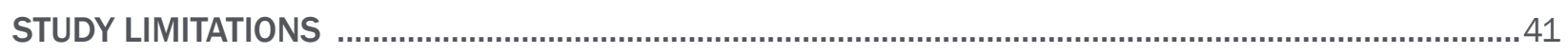

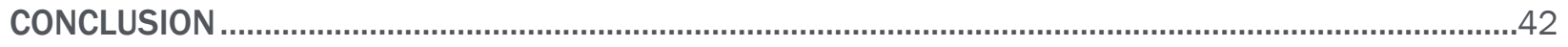

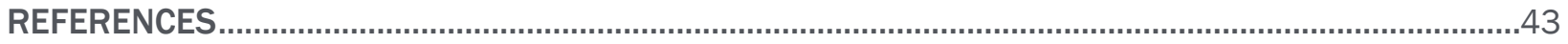




\section{Acknowledgments}

The authors would like to thank the institutions, organizations and persons who provided or helped locate important documents for this study.

We would also like to thank stakeholders involved in the field of family planning at the central level as well as at the regional level for their valuable assistance facilitating the study implementation and for honestly answering our questions.

We would also like to express our profound gratitude to the women from the field sites who agreed to participate in the focus group discussions.

Lastly, we salute the professionalism of the data collection agents who contributed enormously to the success of this study. 


\section{List of Acronyms}

3D

$\mathrm{AcDev}$

ADEMAS

ASBEF

CDA

CHW

CPR

CPT

CSO

DHS

DHS-C

DHS-MICS

DMPA-IM

DMPA-SC

DMT

DRHCS

FGD

FP

FPD

HCP

$\mathrm{HN}$

HPHN

IDI

IEC

IM

IOP

IPM

ISSU

IUD

LAC

LDC

MDGs

MHSA

MSI

NFPAP

NGO
Democratization, Demedicalization, Decentralization

Action and Development

Agency for the Development of Social Marketing

Senegalese Association for Family Well-being

Community Development Agent

Community Health Worker

Contraceptive Prevalence Rate

Contraceptive Procurement Tables

Civil Society Organization

Demographic and Health Survey

Demographic and Health Survey - Continuous

Demographic and Health Survey - Multiple Indicator Cluster Survey

Depot Medroxyprogesterone Acetate - Intramuscular

Depot Medroxyprogesterone Acetate - Sub-cutaneous

District Management Team

Directorate of Reproductive Health and Child Survival

Focus Group Discussion

Family Planning

Family Planning Division

Home Care Provider

Head Nurse

Health Post Head Nurse

In-depth Interview

Information, Education and Communication

Itinerant Midwives

Initial Supply of the Pill

Informed Push Model

Senegalese Urban Health Initiative

Intra-uterine Device

Long Acting contraceptives

Local Development Committee

Millennium Development Goals

Ministry of Health and Social Action

Marie Stopes International

National Family Planning Action Plan

Nongovernmental Organization 


$\begin{array}{ll}\text { NSP } & \text { National Supply Pharmacy } \\ \text { OP } & \text { Ouagadougou Partnership } \\ \text { PNP } & \text { Policies, Norms and Protocols } \\ \text { PPP } & \text { Public Private Partnership } \\ \text { RDC } & \text { Regional Development Committee } \\ \text { RHD } & \text { Regional Head Doctor } \\ \text { RSP } & \text { Regional Supply Pharmacy } \\ \text { RH } & \text { Reproductive Health } \\ \text { SDG } & \text { Sustainable Development Goals } \\ \text { SDP } & \text { Service Delivery Point } \\ \text { SJN } & \text { Siggil Jigeen Network } \\ \text { TFP } & \text { Technical and Financial Partner } \\ \text { TFR } & \text { Total Fertility Rate } \\ \text { UNFPA } & \text { United Nations Population Fund } \\ \text { USAID } & \text { United States Agency for International Development }\end{array}$




\section{Executive Summary}

In Senegal, as in most Francophone West African countries, rates of fertility and of maternal and child mortality are still high, and the contraceptive prevalence rate (CPR) remains low. In light of these challenges, Senegal has positioned family planning (FP) as a national priority, and authorities have made commitments related to financing, organizational structure, and review of health policies related to FP. One of the leaders in FP in Francophone West Africa, Senegal has undertaken various initiatives in recent years to reach its national and international goals. In this context, the 2012-2015 National Family Planning Action Plan (NFPAP) was developed based on the 3D approach, which stands for Democratization, Demedicalization and Decentralization.

As the 2012-2015 NFPAP is coming to an end and the development of a new plan is envisioned, it is critical to document the 3D approach, its implementation, and its achievements. Thus, in collaboration with the Directorate of Reproductive Health and Child Survival (DRHCS), the Population Council conducted this study under the Evidence Project, with funding from the United States Agency for International Development (USAID).

This study aims to document the 3D approach in relation to the NFPAP, to describe lessons learned from its implementation, and to share good practices with other countries in the Ouagadougou Partnership and beyond. This study is intended to provide evidence to support decision-making, especially for the elaboration of the next NFPAP.

This study combines a literature review and qualitative research, including 26 in-depth interviews (IDIs) with FP stakeholders and eight focus group discussions (FGDs) with women of reproductive age (25-44 years old) who were currently using FP or had used FP within the past five years. This study was conducted in the Dakar and Thiès regions.

\section{RESULTS}

The main findings from the qualitative research and the literature review are presented as follows for each key topic:

- Perceptions about FP: FP was generally perceived by both FP stakeholders and female FP users as an area that has advanced considerably over the past five years. For FP stakeholders, this was particularly visible through an increase in the number of FP stakeholders, better organization, better coordination, better community support for and participation in FP interventions (especially by men and religious leaders), better financial and geographical accessibility, and a broader FP method mix. Female FP users cited the keen interest and strong support for FP, and the perception that FP has helped reduce closely spaced pregnancies, contributing to women's well-being and improved health, and that FP is the main reason for the decrease in maternal and neonatal deaths. FP stakeholders felt that some issues remain to be addressed, including criticism from religious communities, costs added to service charges, weak integration of data from the private sector, high rates of discontinuation, lack of budget allocated to FP by the government and duplication of activities by multiple stakeholders.

- Knowledge of the 3D approach: The findings show that only one-fifth of the FP stakeholders knew the 3D approach, and that this lack of knowledge was linked to the lack of communication around the approach. Women did not know about the approach at all.

- Knowledge of actions undertaken in the framework of each " $D$ ": Although few respondents knew the 3D approach, many were able to list actions conducted as part of each " $\mathrm{D}$," once they 
were given the definition. The definition of each " $\mathrm{D}$ " is described in the literature review. For Democratization, the key actions are those undertaken at the political, legal and regulatory levels, those related to communication, those affecting costs, actions taken to develop women's leadership and empowerment, in support of youth, and those related to public-private partnerships (PPP). For Demedicalization, actions include those related to task shifting and to the development of FP at the community level. For Decentralization, actions reported are those related to service provision, decision-making, training and information, implementation of the informed push model (IPM), and the itinerant midwives (IM) strategy. The involvement of local authorities in building health facilities, funding FP, and recruiting qualified personnel (including midwives) was also mentioned. As for achievements, by fostering the involvement of other sectors and stakeholders, Democratization allows, among other things, improvement of knowledge and perceptions about FP, harmonization of contraceptive prices, expansion of service provision, and increase of women's leadership. Through task shifting and community-based distribution, Demedicalization helps broaden the skills of Community Health Workers (CHW) and bring services closer to the population. Lastly, by fostering ownership and accountability at all levels, Decentralization allows access to a larger range of modern FP methods, increase in the number of Service Delivery Points (SDPs), introduction of long-acting reversible contraceptives (LARC) at health posts, and improved product availability in the most remote areas.

- Overview of the 3D approach: Beyond some differences in opinion about which "D" might have contributed the most to progress, FP stakeholders and female FP users agreed that the three "Ds" are complementary and interdependent. The 3D approach was perceived as a good one, especially because of its multi-sectoral nature. Respondents saw it as an innovative approach that should be systematized and popularized for proper stakeholder ownership. FP stakeholders were impressed by this approach and its results, and felt that it should serve as guidance for developing the next NFPAP.

- Perceived effects of the 3D approach: The main effects that respondents attributed to the implementation of the 3D approach were: better geographical and financial accessibility to FP services, an increase in the CPR, capacity building of community-level actors, better acceptance of and support for FP, availability of products, improved knowledge about FP, increased birth spacing, and reduction of maternal and child mortality.

- Sustainability of the 3D approach: The study shows that sustainability of the 3D approach requires widespread awareness of the approach, better involvement and ownership by stakeholders, implementation of strategies for FP commodities security, and motivation and continued training for CHW.

Recommendations: Recommendations are made to the State/Ministry of Health and Social Action (MHSA), to FP stakeholders and technical partners, and to donors.

Conclusion: The 3D approach is a little-known concept, although FP stakeholders operationalize it in their daily activities. Achievements linked to the three "Ds" have contributed to a clear improvement of indicators, and the approach presents great promise for achieving Senegal's development goals. Its clarification and inclusion from the very beginning of the development of the next NFPAP are essential to more quickly boost FP and, therefore, to improve the health of the population and to reduce maternal, newborn and child mortality. 


\section{Introduction}

In Senegal, as in most Francophone West African countries, rates of fertility and of maternal and child mortality are still high, and the contraceptive prevalence rate (CPR) remains low. As a way to avoid unwanted pregnancies, closely spaced pregnancies, and unsafe abortions, family planning (FP) is recognized as an efficient strategy for improving maternal and child health while contributing to the economic and social development of the country.

Therefore, aware of these challenges, Senegal has made FP a national priority. Officials have made commitments at the financial and organizational levels, as well as adjustments to health policies. The adoption of the 2012 - 2015 National Family Planning Action Plan (NFPAP) is proof of this commitment. The ambitious goals of this NFPAP are focused on achieving the Millennium Development Goals (MDG) and more recently, the Sustainable Development Goals (SDG). Based on the concepts of Democratization, Demedicalization and Decentralization of FP, the 3D approach is the cornerstone of the NFPAP.

\section{HISTORY OF FAMILY PLANNING PROGRAMS IN SENEGAL}

Although a French law from 1920 banned the promotion of contraception in Senegal until 1980, the first FP services were introduced in Dakar in 1964 at a private clinic, "La Croix Bleue," and then in the first Association Sénégalaise pour le Bien-Etre Familial (ASBEF) clinic in 1975. Upon the repeal of this law, which was indication of the authorities' support for FP, several national programs were implemented, namely: "Project Population and Family Health" funded by the United States Agency for International Development (USAID), and the "Project for family well-being" financed by the United Nations Population Fund (UNFPA). In 1988, the Declaration of Population Policy, which promotes birth spacing but not limiting births, was the first population policy of the sub-region and the source of future progress in FP. In 1991, the FP National Program was launched. In 2009, the National Health Development Plan (NHDP), which advocates FP as one of the most efficient strategies to save lives and ensure the improvement of maternal, newborn, child and adolescent health, was adopted. Moreover, the multi-sectoral roadmap to fight against maternal and neonatal mortality included FP as a major strategy. The adoption of the 2005 law on reproductive health (RH) was, in addition to technical guidance documents, an important step towards the creation of a political, legal and regulatory environment more favorable for implementation of the FP program. This law clearly names the specific rights granted to Senegalese citizens in regards to RH/FP.

Institutionally, the National Service of Reproductive Health was established in 1997. This structure, in charge of issues related to RH and the development of framework documents, lead to the creation of the Division of Reproductive Health (DRH) in 2001. The Division became the Directorate of Reproductive Health and Child Survival (DRHCS) in 2012, giving a new perspective for effective integration of interventions for maternal health, FP and child survival.

\section{FAMILY PLANNING POLITICAL COMMITMENT IN SENEGAL}

The succession of different programs and changes in the laws and regulations related to RH mark the constant efforts of the government to create a legal, political and social environment more favorable for the development of FP. Since 2011-2012, these efforts have been consolidated and initiatives for repositioning FP have multiplied. Senegal has maintained recent international FP commitments. Thus, in July 2012, at the London Summit on Family Planning, the Minister of Health and Social Action reaffirmed the commitment of the Government of Senegal to make FP a national priority, and Senegal has set ambitious goals for increasing CPR and decreasing 
unmet need. The country also pledged to increase the annual budget allocation for RH from 2.5 to 5 percent, to increase by 200 percent the budget allocation for contraceptive products (from 100 to 300 million FCFA), and to increase the budget for the management of the FP program by 100 percent. The state began to implement its promises by increasing by 100 million FCFA per year the financial resources for securing RH/FP products and by creating a specific budget line of 228 million FCFA for RH/FP.

In 2012, as part of this commitment to repositioning FP, Senegal transformed the Division of Reproductive Health (DRH) into the Directorate of Reproductive Health and Child Survival (DRHCS), which includes the Division of Family Planning (DFP). DFP coordinates the implementation of NFPAP, based on the FP Technical Committee that brings together partners involved in the implementation of this plan. The thematic committees "Demand Creation," "Provision of Service," "Securing Contraceptives," and "Monitoring the Performance of NFPAP (Data Management)" provide assistance in their areas of expertise.

As part of initiatives to promote FP in Senegal, the DFP initiated the National Day of Family Planning with the support of UNFPA, IntraHealth International, and the Senegalese Initiative for Urban Health (ISSU) project. This day was a highlight for mobilizing actors and users around FP. The National Days took place regularly between 2008 and 2013, but since then, no event has taken place as part of this initiative.

\section{EVOLUTION OF FP INDICATORS}

Since 2005, the synthetic fertility index (SFI) has stabilized around 5.0 children per woman. Maternal and child/ youth mortality rates have, however, experienced a gradual decrease from 401 to 392/100,000 live births and 121 to 54/1,000, respectively, between the 2005 Demographic and Health Survey - Multiple Indicator Cluster Survey (DHS-MICS) and the 2014 Continuous DHS (DHS-C).

CPR is usually a good indicator of the effectiveness of FP programs. Also, after having gradually increased until 2010 (from 8 percent in 1997 to 10 percent in 2005 and 12 percent in 2010), the CPR made annual leaps of four percentage points during the 2012 - 2015 NFPAP implementation period, reaching 16 percent in 2012-2013 and 20 percent in 2014.

However, the unmet need for FP remains important among married women. According to the 2014 DHS-C, 25.6 percent of women have an unmet need, including 19.2 percent who want to space their next birth by at least two years and 6.3 percent who no longer wish to become pregnant at all, but do not use birth control.

Among adolescents and youth, who represent an important target for FP programs, CPR for modern methods is still low, in spite of the significant increase in use of FP by this segment of the population: an increase from 1.9 percent in 2010-2011 to 12.3 percent in 2014 among 15-19 year olds, and an increase from 6.0 percent to 12.2 percent among 20-24 year olds during the same period.

\section{BEGINNINGS AND DEFINITION OF THE 3D APPROACH}

Senegal presented the 3D approach for the first time in the sub-region at the conference "Population, Development and Family Planning in West Africa: An urgency for Action" held in Ouagadougou in February 2011. The conference brought together representatives from eight countries in West Africa ${ }^{1}$ (Benin, Burkina Faso, Guinea, Mali, Mauritania, Niger, Senegal and Togo) and their technical and financial partners. As part of an agreement on the need to take concrete steps to accelerate the use of FP services in these countries, this

${ }^{1}$ Ivory Coast joined the initative later. 
conference resulted in the creation of the Ouagadougou Partnership (OP).

Senegal presented the 3D approach, an acronym standing for Democratization, Demedicalization, and Decentralization. For FP, through the 3D approach:

- "Democratization" is designed to facilitate access to services through a multi-sectoral and participatory approach.

- "Demedicalization" aims to allow non-medical staff to provide a range of FP services to vulnerable populations (rural, urban underprivileged, poor and youth), especially through community-based distribution.

- "Decentralization" aims to consolidate health systems at the regional, district and community levels while strengthening good governance, accountability and intersectoral collaboration.

\section{NATIONAL FAMILY PLANNING ACTION PLAN (NFPAP) 2012 - 2015}

Following the Ouagadougou Conference, the Government of Senegal developed the 2012-2015 NFPAP with its partners, and launched it on November 28, 2012. At that point, Senegal was one of the first OP countries to implement a plan to offer all women equal access to quality family planning services. Its ambitious goal was to increase the CPR among married women from 12 percent (as reported by the 2010-2011 DHS-MICS) to 27 percent in 2015. To this end, 350,000 new users of modern contraceptive methods were to be recruited: 125,000 by the public sector, 100,000 by the private sector, and 125,000 at the community level.

The main strategic approach of the plan is based on the implementation of the $3 \mathrm{D}$ approach, with implementation at the operational level based on six priority areas designed to enable:

- The availability of contraceptives by scaling up innovative strategies, community-based distribution of short-acting methods with enhanced task shifting, the broadening of the service with the initial offer of the pill (IOP) and initial offer of injectables (IOI) in order to better reach the most disadvantaged populations.

- The involvement of the private sector in expanding the supply and promoting the use of contraceptives, especially through social marketing, the establishment of a social franchise network and mobile clinics.

- The improvement of supply, especially for long-acting reversible contraceptives (LARC).

- In the public system, an easily accessible quality service, ensuring proper discretion and care for women and especially young people. 


\section{Study Justification}

With the 2012 - 2015 NFPAP coming to an end, there is a need to document the implementation and achievements of the 3D approach that underpins it. This study will contribute to that goal. By documenting the 3D approach through a literature review and qualitative research, this study aims to provide the evidence necessary for decision-making, particularly for the development of the next national FP action plan. 


\section{Objectives}

This study aims to document the 3D approach in relation to the NFPAP, to describe the lessons learned from the implementation of this approach within the NFPAP, and to share best practices with other countries of the Ouagadougou Partnership and beyond. Specifically:

The literature review had the following objectives:

- Assess and analyze existing and available documentation.

- Identify institutions and individuals playing a key role in the achievements of the plan, to allow for a deeper analysis of the implementation of the approach through the qualitative research component.

- Focus the documentation on aspects that have so far received less attention.

Meanwhile, the objective of the qualitative research was to expand on the data gathered during the literature review by:

- Documenting the main contributions of the 3D approach to FP in the context of the NFPAP, from the perspective of interviewed FP stakeholders and female FP users.

- Studying how the results of the implementation of the approach could help improve FP indicators.

- Exploring how task shifting and community-based service provision, which were selected as high impact interventions and implemented as part of the "demedicalization" and "decentralization" strategies in the FP program and included in the NFPAP, were able to improve the supply of FP services, with a particular focus on equity.

This report summarizes the entire study, including the literature review, but places particular emphasis on the qualitative research component. A separate report, "Assessment of the implementation and the achievements of the 3D approach within the National Family Planning Action Plan (NFPAP) in Senegal - Literature Review," focuses on the literature review. 


\section{Methodology}

\section{LITERATURE REVIEW}

The literature review consisted of an inventory of existing documentation solicited from stakeholders and an online search. Information on the implementation of the 3D approach was extracted through reading and thorough analysis of notes and documents obtained. The separate report on the literature review presents the methodology in detail.

\section{QUALITATIVE RESEARCH}

\section{Study Design}

Two regions were selected as study sites, namely Dakar and Thiès. For the Thiès region, the health districts of Thiès, Mbour, Thiadiaye and Popenguine were chosen. These two regions were chosen for the following reasons:

- Dakar, the capital, contains most of the institutions and national and international organizations involved in the FP program.

- The Thiès region was chosen because of the importance of its community network and activities that were deployed for FP. In addition, this region has, after Dakar, the highest rate of use of modern contraception (24.8 percent). The demand rate satisfied by modern methods is also the second largest in the country, reaching 48.4 percent (ANSD and ICF International, 2015).

\section{Study Population}

The study populations were:

- FP stakeholders, including:

- Policymakers, especially parliamentarians

- Government officials

- Local authorities involved in each " $\mathrm{D}$ ", including members of the region and district management teams

- Project and program heads and managers;

- Representatives from national and international non-governmental organizations (NGOs)

- Representatives from civil society organizations (CSOs)

- Women of reproductive age, from 25 to 44, who were current FP users or had used FP within the last five years. They are also called female FP users in this report.

\section{Data Collection and Recruitment Procedures}

\section{Collection Tools}

Three collection tools were developed, namely:

- In-depth interview (IDI) guide for FP stakeholders. This guide covered general information on the type of stakeholder, his/her perception of FP, his/her knowledge of the 3D approach, perceived 
effects of the 3D approach, his/her perception of the sustainability of the approach, and his/her overall view of the 3D approach.

- Focus group discussion (FGD) guide for female FP users. This guide included questions relating to the women's perceptions about changes in the field of FP in the last five years, their knowledge of the 3D approach, perceived effects of the 3D approach, their perceptions on sustainability of progress and lessons learned for FP programming.

- Data collection form on the characteristics of participants in the FGD and their experiences with FP.

\section{Participant Recruitment and Data Collection Proceedings}

\section{IN-DEPTH INTERVIEWS}

In the Dakar region, the IDIs were conducted by the Population Council research team and took place between August 18 and September 9, 2015. The identification of key stakeholders was initially carried out in collaboration with study partners, namely the DRHCS and the team from the USAID Senegal Health Office. The identified stakeholders were contacted by official letter to request the collection of documents at their level. They were then contacted again to request their participation in an in-depth interview. Follow-up was conducted by telephone for stakeholders who did not respond to the written request. Other stakeholders were identified through a snowball approach. The selection stopped when all contacted actors had been interviewed, had expressed their unavailability or had not responded to written or telephone attempts, at a date determined by the research team.

In the Thiès region, the IDIs took place from September 30 to October 13, 2015 with officials of the Medical Region, the health districts of Thiès, Mbour, Thiadiaye, and Popenguine, and other FP stakeholders. Early in the process, an information letter was sent by the DRHCS to the Medical Region. Then an official letter was sent to each FP stakeholder identified to explain the study and request an appointment for an interview.

At the beginning of each interview, an informed consent form was read and voluntarily signed by the participant. The interviews lasted an average of one hour and were recorded with permission. All interviews were conducted face-to-face in a place chosen by the respondent.

\section{Focus Group Discussions}

The FGDs were held in the health districts of Mbour, Thiadiaye and Popenguine from October 5 to 16, 2015. These were led by four data collection agents recruited for this purpose. In order to facilitate discussions on the sensitive issue of FP, collection agents were all women. They were first trained on the presentation of the 3D study and the aspects of conducting qualitative research and ethics. The training was also an opportunity to become familiar with the collection tools, to have them translated into Wolof, and to pre-test all the tools before the actual collection. The collection agents were then divided into two teams, each composed of a moderator and an observer.

The participant selection criteria for the FGDs were: i) between 25 and 44 years of age; ii) currently using FP or having used it at some point during the last five years; iii) obtaining FP in a public facility, or from a community health worker, an NGO, or a non-profit private structure; iv) accepting that other FGD participants would learn her FP status.

To recruit participants, RH coordinators contacted community stakeholders (relais, head nurses, Bajenu gox, Community Health Workers (CHWs)) for assistance identifying eligible women. After compiling a list of 
potential candidates identified by community stakeholders, women were selected by simple random sampling. Since FP use is often hidden in Senegal, potential participants preferred meeting in health facilities (rather than home visits) for the research team to verify that they met the eligibility criteria and to explain the study. If the woman agreed to participate, information on the FGD (date and time) was given to her. If she did not want to or could not participate, she was thanked, and the process was repeated until at least eight women had agreed to participate in the FGD.

The FGDs were conducted in Wolof and were recorded after explicit agreement of the participants. The personal data of each participant was collected individually. Each FGD began with a reading, explanation and signing of the informed consent form. Then the moderator explained the study again and the guidelines for the FGD. During the actual discussion, the moderator was responsible for leading the session and the observer for taking notes and recording the discussion. The discussion sessions lasted an average of 1 hour 30 minutes.

\section{Data Collection Challenges}

When collecting data, teams encountered some difficulties in the field, including:

- Conflict between the collection schedule and that of local actors, often sue to the local actors' activities (meetings, reviews, workshops, and so forth).

- Difficulty having community actors identifying proposed women for the FGDs who met the eligibility criteria (including age and estimated period of use of FP), which sometimes caused delays in the recruitment of participants.

\section{Data Management}

Particular attention was paid to data management. IDIs and FGDs were recorded and transcribed in French on Microsoft Word. To preserve the anonymity of participants and the confidentiality of any information that would identify and locate respondents, an encryption system was established. In addition, anonymized transcripts as well as the IDI and FGD audio files were kept in a secure location, in accordance with the Population Council's data protection criteria. Access to the data was limited to the research team.

\section{Data Analysis}

Content analysis was used for data interpretation. It combined a descriptive approach and an inductive approach to present an overview and to identify themes and patterns that were then used to build typologies. This helped to more precisely meet analytical requirements that take into account different orientations defined in the research protocol.

The collected quantitative data, including demographics of participants in the FGDs and their experiences with FP use, were analyzed in Epi Info 7.

\section{Ethical Aspects}

\section{Ethical Approval}

The research protocol received ethical approval from the Population Council Ethics Committee and from that of the National Ethics Committee for Health Research (CNERS) of the MHSA, as well as administrative authority from the Directorate of Planning, Research and Statistics of the MHSA. 


\section{Informed Consent}

Free, informed and written consent was obtained from each IDI respondent and each FGD participant. Information and requirements for participation in the study were read to the participants, who expressed their agreement and signed the informed consent form.

\section{Confidentiality}

Several measures were taken to ensure the confidentiality in IDIs and FGDs: they were conducted by experienced interviewers, in the most private places possible; the exact location is not noted in any publication; computers were protected by passwords; notes and records were kept in locked cupboards in the office of the Population Council. Once transcripts were completed and verified, and research reports published, notes and records were destroyed.

\section{Anonymity}

To ensure the anonymity of respondents and information collected, no identifying information was recorded on the interview notes, recordings or electronic transcripts. The data was kept separate from identifiers. The anonymity of the FGD participants has been assured through the use of identification numbers. 


\section{Results}

\section{DATA COLLECTION OVERVIEW}

As part of the literature review, eight websites were consulted. Six presentations and 33 documents were collected, including reports (on studies and activities), articles, informational letters, and strategic documents/plans.

In the qualitative research component, 26 in-depth interviews were conducted, 15 in Dakar and 11 in Thiès. The table below provides an overview.

\section{TABLE 1 | OVERVIEW OF IN-DEPTH INTERVIEWS}

\begin{tabular}{|l|l|c|}
\hline \multicolumn{1}{|c|}{ Site } & \multicolumn{1}{|c|}{ Target Population } & Number of IDIs \\
\hline \multirow{5}{*}{ Dakar } & Parliamentarians & 1 \\
\cline { 2 - 3 } & Health officials, central level (government officials) & 4 \\
\cline { 2 - 3 } & Financial and technical partners (FTP) & 2 \\
\cline { 2 - 3 } & NGO representatives & 7 \\
\cline { 2 - 3 } & NGO network members & 1 \\
\hline \multirow{5}{*}{ Thiès } & Policymakers & 5 \\
\cline { 2 - 3 } & Local health authorities & 5 \\
\cline { 2 - 3 } & FTPs & 1 \\
\cline { 2 - 3 } & District Management Teams (DMT) members & 26 \\
\hline \multirow{2}{*}{ Total } & & 4 \\
\hline
\end{tabular}

A total of 80 women were reached through eight FGDs, carried out with groups of 8 to 12 women. The women were divided into two age groups: 25-34 year olds and 35-44 year olds.

Available data on participants' characteristics indicate that most women were married (75), with a small number of others (3) divorced. They were all Muslim. The number of living children averaged 3.9 (between 0 and 9 children). 16 women had reached secondary school level, 28 had reached primary and 34 had no educational background or had attended Koranic school. Thirty-four women were traders and vendors, 30 were housewives. There were also seamstresses, relais, health workers, nurses, restaurant workers and students.

In regards to their FP experience, 69 women were current users and nine had used it within the last five years. Among current users, 35 had opted for injectables, 17 for implants, 14 for the pill, one for an intra-uterine device (IUD), and one had undergone female sterilization. The women had used their method for four years on average. Twenty-nine women were not using any method before using their current method. The majority had obtained their method from a midwife (64) or at a public health facility (67). Two had benefited from the services of a mobile clinic.

Among past users, five had used injectables, three the pill, and one the implant. Seven women had stopped FP to become pregnant, the two others for fear of potential effects related to long use or because of a missed period. 
Two FGDs were conducted with each age group in urban/peri-urban and rural areas. The table below presents the overview.

TABLE 2 I OVERVIEW OF FOCUS GROUP DISCUSSIONS

\begin{tabular}{|l|c|c|c|c|c|}
\hline \multirow{2}{*}{ Health District } & Locality & Age Group & Setting & $\begin{array}{c}\text { Number of } \\
\text { FGDs }\end{array}$ & $\begin{array}{c}\text { Number of } \\
\text { Participants } \\
\text { per FGD }\end{array}$ \\
\hline \multirow{3}{*}{ Mbour } & Mbour & $25-34$ & Urban & 1 & 10 \\
\cline { 2 - 6 } & Thiadiaye & $25-34$ & Peri-urban & 1 & 10 \\
\hline \multirow{3}{*}{ Thiadiaye } & Fissel & $35-44$ & Rural & 1 & 10 \\
\cline { 2 - 6 } & Sandiara & $25-34$ & Rural & 1 & 10 \\
\hline \multirow{3}{*}{ Popenguine } & Popenguine & $35-44$ & Peri-urban & 1 & 10 \\
\cline { 2 - 6 } & Sindia & $35-44$ & Rural & 1 & 10 \\
\cline { 2 - 6 } & Ndayane & $25-34$ & Rural & 1 & 10 \\
\hline Total & & & & $\mathbf{8}$ \\
\hline
\end{tabular}

\section{FP PERCEPTIONS}

The results from interviews with the FP stakeholders and from the FGDs show that FP was generally seen as an area that has experienced many advances over the last five years.

\section{Perception of FP Stakeholders}

According to FP stakeholders, the most notable positive change was the expansion of the number and diversity of stakeholders involved in the field. For many stakeholders questioned, the fact that contraceptive use is now seen not only as a health issue but also as a development issue has led to the involvement of other state institutions outside the MHSA, like the Ministries of Youth, Family, and Education. This was illustrated by these comments from an NGO representative, "... the administrative authorities today are present at FP activities. This is both officials at the central level as well as those decentralized, such as governors, prefects who chair the meetings and set up monitoring committees for example, recently in Saint-Louis where a Regional Development Committee (RDC) was chaired by the Governor and a monitoring committee was set up."

Beyond the state's leadership and commitments, the stakeholders also noted better engagement and involvement of parliamentarians, CSOs, NGOs and technical and financial partners (TFP) who have shown great interest in FP through their support for development and implementation of the 2012-2015 NFPAP.

"Today there are many more development partners who are a little more interested in mother and child health [and] who get involved in that context. So that too is a good change, because before it was almost only US AID who intervened and people automatically said 'ah, Americans, they come to limit the births of our children.' And that was the perception that people had. Now, it is good that there are multiple partners involved. In principle, it is better perceived, much better perceived" (NGO representative). 
FP now appears as a more organized field, with a vision, strategies and implementation plans. It is the subject of better coordination through the establishment at the central level of a Technical Committee that meets regularly and brings together all stakeholders, both government and TFPs, to initiate discussions on technical and financial issues. This consultation framework did not exist before. The RH Products Security (RHPS) Committee provides coordination at a central level. It manages national quantification, especially with the contraceptive procurement tables (CPT), and monitors the dashboard that allows for the provision of products at all levels and monitors the supply by backer. "Before we did not feel this coordination, each partner was trying to work in a field and maybe there was no consultation between the technical and financial partners ... the different authorities of coordination have enabled us to avoid duplication in activities and see the gaps a little." (Government official). Also, at the regional level, the establishment of Regional Development Committees (RDC) and Local Development Committees (LDC) has brought together all the stakeholders, even if the meetings are not regular, as noted by this local health official: "Here in Thiès, we do not have that problem. All stakeholders are involved in RDCs and LDCs. What might be improved is the regularity of these moments of sharing."

Furthermore, some people, particularly at the regional level, emphasized greater community acceptance and even participation in FP interventions, specifically by men and religious leaders. This was attributed mainly to communication activities, with the observed change in the discourse and awareness messages promoting the importance of birth spacing through the slogan "Moytou nef." The "nef" [closely spaced pregnancy] is now considered from a traditional and religious standpoint a reason for women's exhaustion.

'Now with the concept 'Moytou nef' people have understood better. The proof is that yesterday I had to train religious representatives because Popenguine still has this specificity. In the community field, we're lucky. In this commune, we trained 23 religious representatives, Imams and Ulemas on FP. But with the 'Moytou nef' concept, they expressed ideas that if we had explained this before, there would have been no problems. They say that, in Islam, birth interval exceeds at least 2 years" (DMT member).

Today, in addition to seeming more accessible to people both financially and geographically, FP is seen as an area that has better quality human resources, as a result of multiple trainings, and that offers more choices for women, even at the community level, due to a wider range of methods.

In the opinion of both national and regional level actors, there are still aspects that need strengthening despite all these advances. Thus, the existence of critics belonging to religious communities was for some an obstacle to achieving higher indicators. Some actors also pointed out that the gender aspect has not been adequately reflected in the information, education and communication (IEC) efforts directed at communities, which they believed would explain the reluctance of some men to support FP. As this source highlighted: "In Africa, economic power is still beld by men, it is important that we could associate them with decision-making... As long as it was the women who spoke to men, men would not listen to them. I think we need more and more men interested in this field. It is extremely important that men are aware, that they know they are the first to benefit from this planning before the women because if we have a woman who is sick all the time, children who are sick all the time, the man is the first to feel it. So this gender approach is extremely important" (Government official).

Moreover, many believed that despite the lower prices advertised for contraceptives, as described in the literature review, FP services are still not accessible to all sections of the population, since in addition to the product price, service costs contribute to making them out of reach in some areas. A source said: "When the product is cheaper but the overall service from the provider is expensive, the act itself will drown feasibility. Take, for example, just the placement of an implant that will require xylocaine, compresses, all these inputs that contribute to this act will be expensive while the product to be inserted itself will cost around 500 francs" (NGO Representative). 
Difficulties in integrating private sector data (clinics, private medical practices, pharmacies, companies' medical services), which many stakeholders believe represent a real potential to boost CPR, contributed to reinforcing the negative perception of FP. Many also believed that FP usage data is underestimated, which raises question of data reliability. The following words illustrate this observation: "T've just finished an audit of the data quality. For example, just for the case of Dakar, where there are many more private structures than public structures, particularly, the private sector data is not in our data. So to say that the data we have is underestimated, fortunately there is the Continuous DHS allowing us to have an estimate of CPR. But we have to fight for a collection system, reliable data recovery, so I think this is a weakness of the program" (Government official).

Furthermore, for many actors at both the central and regional levels, keeping women in the FP program deserved special attention, in view of the numerous cases of discontinuation.

Another aspect that was emphasized and was also seen as a weakness of the program concerns the lack of qualified personnel, a situation that has spawned the use of community staff, a group for whom motivation is a concern. The remarks of this NGO representative illustrate this point: "They are there but there is a lot of volunteering in health, a lot of volunteering. And you cannot ask for results from people for whom motivation is a problem. This problem exists."

In regards to securing products, certainly the state has made considerable efforts to improve availability; however, the budget allocated by the government to FP was considered inadequate by many stakeholders.

Furthermore, although the DRHCS is trying to unify actions, the synergy needs to be strengthened because some stakeholders still found that there was a lack of coordination of interventions, sometimes causing duplication and overlap in activities.

\section{Perception of Female Users}

As for female FP users, FP was also seen as a practice that has undergone positive changes for the most part. Indeed, they emphasized a genuine enthusiasm among women and massive support for its use, which they attributed to several factors, including:

- Increased knowledge about FP: Most women thought that people have a better understanding of the advantages and disadvantages, through increased awareness and communication activities. Therefore, they better understand FP issues.

"Women like me were scared of FP. But they were made so aware that now, most of them do not hesitate to go to the hospital for FP, because we were told 'if you do FP, before having a child again, you will face many difficulties.' But we were made aware of all of this. We were asleep before, now we are awake to all of this" (FGD, Fissel).

Or according to this participant: "Women like me had very closely spaced pregnancies but this is no longer the case. Pregnancies are spaced out and it's a good thing. Women are awake now. Before, we didn't know anything. Closely spaced pregnancies tired us out, but now, thank God, Alhamdoulilab" (FGD, Mbour).

- Affordability: The lower cost of contraceptive methods has, according to some women, greatly contributed to their use.

"Before, you would see a woman say 'I can't go because I don't have the money'. But now, they've lowered the cost, it is almost free. FP products that cost 500 francs before cost 200 now, it's dirt cheap" (FGD, Fissel). 
- The increase in the types of methods available: The diversity of contraceptive methods increases women's choices and allows a woman to opt for the method that works for her.

Furthermore, the use of FP was also seen as a contributing factor to the reduction of closely spaced pregnancies, and the increased welfare and thriving of women. Even better, the participants noted that by spacing births, FP was the main reason for the decline in maternal deaths.

"When there was no family planning, pregnancies were frequent. Before your child was a year old, you were pregnant again. It is used for birth spacing. You can go 2 years without getting pregnant again. Even, if you want to, you can go 3 years before another pregnancy. It's really good" (FGD, Ndayane).

"We salute family planning because it has been great for us women. Maternal and newborn deaths have been reduced and FP is the reason for that. Before, a woman died giving birth but now, with family planning, that doesn't exist anymore. Births are spaced and you have time to take care of your kids. Really, family planning has been great for us" (FGD, Popenguine).

"Now, it is rare to see a woman die in childbirth" (FGD, Popenguine).

\section{KNOWLEDGE OF THE 3D APPROACH}

The information gathered through in-depth interviews shows that the 3D approach was known by only about one-fifth of the stakeholders in the FP field. This ignorance was even more noticeable in the Thiès region where almost all people interviewed said they heard about it for the first time during this study. This ignorance was linked, according to one of the respondents, to lack of communication about the approach.

Among the few FP stakeholders who claimed to have heard of it - at the launch of NFPAP for some or at a meeting of the FP Technical Committee for others - very few were able to give an exact definition, or even information on its date of onset and its potential applications in fields other than FP. However, a source said that this approach was stated for the first time in 2010 in Kigali, at an FP meeting, before the 2011 Ouagadougou Conference to which the stakeholders and documents gathered for the literature review make reference. In addition, some mentioned that apart from FP, the 3D approach is applied in other areas of health such as maternal, newborn and child health (particularly in the context of the Expanded Program on Immunization (EPI), nutrition, and the use of the vacuum at health posts), and malaria.

A similar lack of knowledge of the 3D approach was found among female FP users. Indeed, no participants stated that they had ever heard of this approach.

\section{KNOWLEDGE OF ACTION TAKEN UNDER EACHE “D” OF THE FRAMEWORK DEMOCRATIZATION}

Although few respondents knew the 3D approach, many of them cited actions that had been undertaken as part of "Democratization" once the definition of the concept was given. Recognized actions are described in the literature review.

\section{Actions Cited by FP Stakeholders}

\section{Actions Taken at Policy, Legal and Regulatory Levels}

Many stakeholders drew attention to the authorities' commitment to making FP a priority issue and the genuine political will to make services accessible. As a member of DMT in Thiès said, "That - we felt because for years it 
was only the health workers who talked about FP, but if the President, now the Minister and everyone is talking about it, there is political will." This parliamentarian confirmed: "My first action was to organize an awareness seminar on family planning."

This political will was manifested through several acts, such as the creation of the DRHCS, with the DFP within it (see literature review for details). In addition, other sectors and stakeholders have been involved in FP issues and advocacy tools have been developed, such as the ENGAGE tool to raise awareness of the contribution of FP in both improving the health of mothers, newborns and children as well as in the fight against poverty.

The State has also committed to the budget plan, including the announcement by the Ministry to increase by 200 percent the budget line dedicated to contraceptive products. Since then, many stakeholders said they have found that efforts have been made in this direction by the MHSA, but also by the Ministry of Economy and Finance, as indicated by a government official: "We went from 50 million, after it rose to 100 million to 150 million and now it is at 200 million, and we risk bringing it to 300 million. So even advocacy will continue." These remarks were corroborated by those of another government official: "T believe that before the line was 65 million, then we went to 100, then to 200 million, in 2016 the line will be 300 million. Today, when I came out of the meeting held at the Ministry of Economy and Finance, I know that we will increase a line again for the DRHSC, as a direct compensation with the key system and the direct financing with US AID. So really the government is making efforts around that. I think this is a good thing."

Moreover, Policies, Norms and Protocols (PNP) are revised regularly, to enable decisions to be updated. Also, Senegal has a security plan for essential commodities for mother and child health, which includes contraceptives on the list of essential medicines. Its implementation involves many initiatives from partners. An NGO representative says: "At first contraceptives were managed directly by the DRHCS. Now there was a major change to the inclusion of contraceptives in essential medicines... Now, with the integration of contraceptives in essential medicines, it has also been democratized. The fact that contraceptives are considered essential medicine is a part of democratization."

Also, the strategic plan for community health, which dates from 2014, was mentioned by some as a policy that began to define this democratization at the community level and has established a legislative and regulatory framework for interventions. This is evident from the remarks of this NGO representative: "I saw that the community health policy has contributed a lot to the access to services. And the field has proven it to us. Today around all health centers, we feel a community mobilization that provides access to FP services."

Regional actors have stressed the expansion of health infrastructures, including the distribution of health posts every five kilometers. As for the strategic option in the Thiès region, it ensures that all health posts also have midwives, as reinforcements for Head Nurses (HN).

Regarding service provision, many stakeholders argued that democratization is also ensuring quality human resources. Thus, the many training programs initiated for health workers, with a particular focus on counseling in order to facilitate women's informed choice, would have significantly contributed to democratization. A regional FP actor stated, "Now, the staff is also better trained in FP through the many courses offered on different methods, so that clients can now make an informed choice." And another concurred: "Very often training courses are organized for health personnel because medicine is changing and we have more and more new methods to integrate into the range, as recently with Sayana ${ }^{\circledR}$ Press, and even there is talk of a new method, the vaginal ring, which will soon join the range."

\section{Communicative Actions}

According to FP stakeholders interviewed, the activities that have most democratized FP services include the national communication campaign "Moytou nef" that was initiated in the framework of the implementation of the NFPAP (see literature review). From their point of view, it has been the communication activities that have 
most effectively reached the various targets, especially men and religious leaders. The awareness campaigns through the media (TV, local radio) and posters have enabled people to take a new outlook on FP and to better adopt it. Additionally, after being trained, religious associations and networks of Imams and Ulemas were given the responsibility of raising awareness through sermons at mosques and neighborhoods, especially with men. A member of the Mbour DMT said: "Religious men are helping us with awareness around family planning especially with men." And another in Popenguine confirmed: "With the network of 'religious representatives', as we call them in our district, we had training just the day before yesterday about the religious arguments on family planning. So they, too, play a role that is pretty important because where I cannot know the 'suras' or 'aya' in order to convince someone, them, they can use this language and be understood... with them, there is still more and more awareness by the people who were reluctant at first and who are beginning to accept."

\section{Actions Affecting Cost}

For most stakeholders, the memorandum on prices issued by the Ministry of Health in 2010, and in principle, posted at the facility level, is a good example of democratization, to the extent that it has harmonized and reduced the prices of contraceptives (see literature review). Following this, client contributions became symbolic, and it is theoretically the same at all levels of the health pyramid. The remarks of this member of Thiadiaye DMT are quite illustrative: "There is a harmonization of product prices. What we had noticed is that for certain products a district could sell it at 1,000 FCFA, another at 1,500 FCFA, and another at 500 FCFA. Now all districts, all delivery points must respect the price; the most expensive product is 500 FCFA."

Some contributors, such as Marie Stopes International (MSI), have gone even further by making the service free through service provision channels such as mobile teams, which means that the reduction in the price of contraceptives (to free contraceptives in some cases), combined with making services closer, virtually eliminates the cost of services in some areas.

"Financially also, there was movement because for some family planning methods, people were forced to come to the bealth center, now at the nearest health post, they can access that family planning, so I think that financially, the cost has really declined for the population, and the cost is even non-existent with respect to certain activities, such as mobile clinics and the like that offer free methods which go out to the people and reduce the cost of transportation, etc." (Health Official, Mbour).

\section{Leadership and Empowerment of Women}

As a FP champion, Madam the Minister of Health is, in the opinion of some stakeholders, a good example of women's leadership. Furthermore, the fact that women parliamentarians are increasingly engaged in FP issues contributes to strengthened leadership. A technical partner noted that: "Some among them have also participated in the last meeting of the Ouagadougou Partnership in Paris." Moreover, to magnify women's leadership, apart from the finding that "the network of community actors is made up of 90\% women," others highlighted the existence of networks of women who support/accompany MHSA in advocacy. This government official testified: "In the field of FP there are networks of women, who are very active and who help us a lot. I mean the women doctors, the Association of Women Doctors (AFEMS), the Network. Siggil Jigeen (RSJ) are women and give a lot of support to the Ministry of Health, the Association of Women Lawyers (AJS), which greatly helps the Ministry of Health in the area of advocacy. I think that in terms of women's leadership, women are very involved in FP."

But for many stakeholders, it is through the "bajenu gox" program (see literature review), which has been revitalized in recent years, that leadership has really affirmed itself through outreach to men (and mothers-inlaw), who are the household decision-makers. A source said: "I think bajenu gox were also helpful for promotion of family planning. And what is interesting to note is that this female leadership there, it has helped to strengthen the involvement of men. Because, in reality, the problem it was not women." 
Regarding the empowerment of women, although some sources believed that this has not been achieved, others pointed out that the many awareness campaigns conducted within women's organizations have helped make women less dependent in regards to their husbands, particularly concerning the management of their health needs. The promotion of economic activities, as well as the advent of mutual health funds, facilitated their empowerment even more. The remarks of this technical partner are a good illustration: "With the many awareness campaigns for female associations and groups, women have now realized that they are able to take responsibility for their own health, especially in FP. Traditionally, the woman depended on her husband to ensure her health. But today with the incomegenerating activities in which many women are active, they can support themselves without having to go through the husband. So they are becoming more independent." These remarks were corroborated by those of a member of DMT in the Thiès region: "Even in their activities, people have been organized. That is with income-generating activities. I know I can take care of myself, I don't have to depend on my husband, I can simultaneously support my bealth and the health of my children. Around that in any case there is awareness. Here we are. Change is always long in coming, it cannot be measured immediately, but still, we feel that it is moving."

\section{Actions for Young People}

Although the NFPAP specifically targets married young people, stakeholders have noted certain actions in the context of democratization of FP services for this target group generally, including:

- The creation within the DRHCS of a Division for Adolescent/Youth RH

- The development of a Strategic Plan for Adolescent/Youth Health

- The establishment at health facilities, particularly at the regional level, of a Youth Space/Teens Corner where they can have access to information related to RH or can be referred. This not only complies with the "Standards of Health Services Adapted for Teens/Youth," including standard 2 (see literature review), but especially addresses the specific care of this population. A government official noted that: "In each region, there was a Teen Advice Centre. But us at the ministry, we thought it was not democratic. We have no right to give that opportunity only to the residents of the major towns of the regions. And maybe what we needed, the best way is to be open at health posts, to have a little space there, a space where there is a team to have peer discussions, allow them in any case, to ask any questions and to have the service provision that is available."

- The establishment, with support from partners, of youth networks and associations that are very involved in FP (e.g. network of young FP ambassadors, RESOPODEV, and so forth)

- The training of peer educators for youth awareness on RH issues, including FP: "They were selected in each village. In each village there is a representative who speaks to young people. If there are activities, they gather in order to be stronger and be heard." (DMT Member, Popenguine).

Some sources emphasized advanced partner strategies in place for students, such as the establishment of youth centers/spaces in some universities, which are sometimes perceived by some actors as mobile clinics, as in this remark: "MSI helps us a lot with mobile clinics at the UCAD [Cheikh Anta Diop University] and at the Gaston Berger University. They do a great job in this area" (Government official).

\section{Public Private Partnership}

The study shows that under the public-private partnership (PPP) for commercial purposes, numerous strategies have been implemented to democratize FP through the involvement of the private sector in the provision of services. Most stakeholders who commented on this issue mentioned the existence, since late 2012, of a 
social franchise network called "Blue Star" created in the ISSU project ${ }^{1}$ with the participation of members of the consortium, including MSI, which aims to involve private health facilities in providing FP services (see literature review). These structures have technical (training), equipment and logistics support. At the regional level, interventions are also conducted in the health districts in partnership with private health structures. A member of Thiès DMT said:

"In the region of Thiès we established a partnership with the private sector to be better involved in the provision of FP services. In this context, they receive the same training we offer to the public sector staff, they are invited to meetings and receive products under the same conditions as the public sector through the Push Model."

The work done by MSI as part of the ISSU project, with a network of 82 pilot pharmacies, was also noted. This allowed for the integration of FP on their shelves, for the promotion of demand and for the monitoring of distribution through data collection.

In addition to private clinics, the involvement of large companies' medical services (SENELEC, SONATEL, SONES), through contracting as part of the Informed Push Model (IPM) initiative, was also mentioned by some stakeholders. In addition, many private structures in the district are enrolled under the Tutoring Plus initiative (see literature review).

All agreed on the idea that the aim of all these interventions, beyond facilitating access to FP services, was to collect data from the private sector to integrate with data from the health districts.

Also in the area of PPP, in addition to service provision, some government sources discussed the collaboration with foundations (e.g. Sonatel Foundation) for the mobilization of resources for FP. Steps were also outlined for a partnership with the mining sector in order to involve them in FP.

Regarding the PPP with the non-profit private sector, some sources noted a variety of things that have been done, such as the implementation of the National Strategy for Contractualization of Health Services and its operations plan. Likewise, with the implementation of the National Strategy for Community Health, the government has managed to involve the non-profit private sector. One NGO representative stressed that: "Recently, the Ministry of Health has established a national strategy for community health. And all of this is done with partnerships, with non-governmental organizations, with other sectors that are not profitable but which are private. An NGO is a private structure, but not for profit. From this point of view, I see that there are many openings that exist. There is a great partnership, because there are large programs funded by USAID which are providing support to the program. And so I think. there are Senegalese NGOs that are there."

\section{Actions Cited by Female FP Users}

Women have, for the most part, observed two actions for the democratization of FP services in the past five years.

First were outreach activities through TV and radio (including community radio) as part of the campaign "Moytou nef" or by health agents and bajenu gox in connection with home visits. According to the women, these activities aim to improve people's knowledge about family planning, particularly men, with the support of religious leaders.

${ }^{1}$ This network consists of Guédiawaye, Pikine, Keur Massar and Mbao for counseling, marketing and client referrals to competent facilities. 
"On TV, there are lots of shows on the topic, they even talk about family planning. They are now working with Imams to improve access to family planning. I have personally seen it on TV. This is the Imam who is on Sud FM. What's his name again ... there is a lot of talk about family planning. I saw it personally. He said at first he was a detractor of family planning, but after much reflection, be said that family planning is not bad" (FGD, Ndayane).

'In regards to family planning, we talk about 'Moytou nef' all the time. On the radio, on TV, they talk about it. Even those who are uneducated know what birth spacing is" (FGD, Mbour).

"With democratization, even men are awakened because they, themselves, remind their wives about their appointments. They are the ones who say 'when is your appointment?' Or 'bave you taken your pills?' They are awake now. ... They save more money because if you have a baby, 3 months later you get pregnant again, you're not healthy, your child is sick, your husband will have no means" (FGD, Mbour).

The other action conducted that, according to most women, contributed to democratization, was the decrease - and in some cases, elimination - in cost for FP services.

"Democratization means that before you paid 1,000 FCFA for family planning, now it's free, you know that it is democratized" (FGD, Mbour).

"I saw that planning is useful, we have democratized it, that is to say, it's free so that everyone has access, both those who have the means and who don't. In short, we have democratized it" (FGD, Mbour).

In addition, a source pointed out that the fact that the authorities consider contraceptive use as a human right is a democratic action in and of itself.

"It's the fact that married women, like unmarried women, all women who are of reproductive age and wish to use family planning are entitled to it without being asked questions, those are the measures taken by the authorities" (FGD, Mbour).

\section{Successes and Achievements of Democratization}

Many successes and achievements were associated with democratization.

For FP stakeholders, these included:

- Better perception of FP by the general public.

- Increased knowledge of FP among the general public (because they were better informed)/improved access to information.

- Better involvement of other sectors (private commercial and private non-profit) in FP interventions.

- Easier and more equitable access to FP (from a financial perspective).

- Increased involvement in FP at the community level. A government official said: "They have realized that it is no longer the business of the bealth sector but it's more the business of the community. Most agents are not paid, so they volunteer, and that, that requires commitment. At least it means that they joined the cause, so the awareness was well done. They are really aware and they are concerned. So these are also factors of success."

- Broader FP method mix.

- Start of integration/inclusion of data from other sectors.

- Updated programs for the private sector through the training received.

- Increase in women's empowerment. 
For female FP users, the successes of democratization were:

- Improvement in people's knowledge.

- Increased FP use by women.

- Affordability of FP services.

- Birth spacing.

- Better involvement and support from men.

"Currently it is men who require their wives to go practice FP. Because I have a neighbor that I often teased by saying 'B.B.G: Boote, biir, Gaddou' [wear on the back, wear in the belly, wear on the arm]. But when she gave birth, her husband came to my house. When he arrived, he asked me 'what can I do so that my wife uses FP?' I told him 'go to the hospital'. He said 'please take her'... Currently, many men have imposed FP on their wives because the way they [the women] care for them makes them [the men] bappy” (FGD, Fissel).

"The fact that our husbands accept it is part of what democratized it. If the heads of households agree, it becomes more widespread. It is better to ask you to leave than to try to hold you back. They are among those who have democratized FP services" (FGD, Ndayane).

\section{Limitations of Democratization}

Despite efforts to democratize FP services, there are, according to interviewees, some areas for improvement.

For FP stakeholders:

- Insufficient involvement of the private sector, including pharmacies, in the provision of FP services: currently, full participation of the private sector, which would translate into real opportunities in terms of coverage, is hampered by restrictive legal texts.

"For real involvement of the private sector, we must revise these texts, some of which are barriers to provision. If we take the case of service supply, we had to support the Ministry on initiatives such as the initial offer of the pill at the community level, but in pharmacies, there are still burdles despite the fact that the pharmacy is an entity present at the community level... If this is done in huts with proper supervision, why not in pharmacies? I think we can create a space for counseling. Pharmaceutical agents require training in FP services. At huts, not all methods are offered, so why not consider extending this experience to the pharmacy? ... I think if we all sat around a table (DRHCS, the private sector and key stakeholders), we could discuss the feasibility of interventions in the sector and constraints in this sector, their involvement in new Ministry policies concerning $R H$, to improve their participation” (NGO Representative).

"There is still much to do because the private sector does not yet feel part of the bealth system. The private sector needs to feel like a stakeholder, and only political will can do it" (Technical partner).

- The lack of application of the memorandum on prices: many interviewees reported that, despite the reduced price of contraceptives, in reality, the cost of service remains high for some clients because of the additional costs linked to service provision by providers.

"Even if the product itself is available, you need cotton, a syringe or other things, it's the client who pays and ultimately, it becomes expensive for her" (DMT Member, Thiès). 
"There is still resistance from providers. For example, women often say 'yes, you say it costs 500 francs. But to insert the implant, you need cotton, gauze, etc. But the midwife told us that we have to pay 1,000 francs'... I asked the partners to give me insertion and withdrawal kits. That is to say a package where there is everything. So there will be no more problems ... Anyway, I continue to advocate. So I think it's still a limitation to what we are doing" (Government official).

"There is the price of the product, but also we add a lot of other costs related to the service and it results in amounts that are not affordable to everyone ... But monitoring the service level, I think it is a big challenge. Somewhere it is the sinews of war. If we could do there that would be nice, it would be very democratic" (NGO Representative).

- Reluctance of some religious leaders and men: although those target populations are increasingly adopting FP as a result of increased communication geared to them, some actors emphasized that some remain reluctant.

"There is still reluctance amongst the religious leaders. At this level, there is work to be done. We must raise more awareness. Especially with men since that is our reality. Here, this is the man who has the power of decision, and usually they are the ones that are in charge of health spending. But also mothers-in-law, because when men are not there, it is they who decide" (DMT Member, Thiès).

- Limited service provision for young people: in the opinion of many actors, despite what has been done for this segment of the population, FP service provision for young people is limited by a number of factors, including socio-cultural and legislative ones, such as the lack of an implementing decree for the RH law.

"What did not go well is in relation to contraception for young people given the cultural barriers as I told you. Given many burdens. Also the State does not want to get carried away on that. So these are points that are challenges for democratization. Because each society has its own culture, has its social norms." (NGO representative)

- Lack of financial support from the State: although efforts were recognized, the participation of the State in funding FP was considered minimal by some actors. These actors also believed that the effective involvement of other sectors would be good (e.g. Ministries of Economy, Youth, Family ...).

"Putting contraceptives in the circuit of essential medicines as well as other drugs, it's a great thing. Now what remains is just State funding. Maybe it's the financial participation of the State in relation to securing medication that needs improvement" (NGO representative).

\section{For Female FP Users}

Among female FP users, the main limitation of democratization concerned service provision for young people. While for FP stakeholders, this component must be strengthened; for most women, it was considered excessive democratization, and may encourage young people to be promiscuous.

'W hat did not work, it's only one thing, I noticed that we provide FP methods to young women, that's not normal. A girl who is not married, we should not be able to offer her a method. Democratization must be limited to women who are married, who manage their households, who manage their spouses, who manage their children. But a girl who will ask a FP method, I do not agree with this. (FGD, Fissel).

"Democratization is important but my concern is about the young people that we integrated into it, I believed that family planning was reserved for married women, those who are tired and want to stop having children and not to unmarried girls... it bothers me 
still, if it were up to me, family planning would be reserved for adults. If young people wish to practice it, well, there are other things we can explain to them ... asking a girl to practice family planning is to ask her to be promiscuous, sometimes it bothers me. (FGD, Mbour).

\section{DEMEDICALIZATION}

The study shows that most respondents, both at the central and regional levels, were familiar with many actions developed in the context of demedicalization (see literature review).

\section{Actions Cited by FP Stakeholders}

FP stakeholders referred mainly to advances observed in relation to task shifting. They pointed out that in regards to FP service provision, it is not only the techniques that have been demedicalized, but also information. For example, the supply of LARCs, including implants and IUDs, by HNs that was hitherto reserved for doctors and midwives. Some actors also mentioned the establishment in 2012 of a training plan to allow matrons and CHWs in health huts better control over communication techniques with respect to counseling, but also to be able to refer women who suffered from side effects to appropriate facilities. This training was also intended to empower matrons and CHWs in IOP, and the initial offer of the intramuscular injectable (Depo Provera $\left.{ }^{\circledR}\right)$ and the subcutaneous injectable (Sayana ${ }^{\circledR}$ Press). Some stakeholders said that it was following the conclusive results of these experiments that the MHSA authorized these practices in 2014 in the form of a circular letter. A source stated that "Although there is no formal law, the MHSA has made changes in the PNP that reference it. For example, when we say that the bealth hut is managed by a matron and the FP products must be available at the but, this assumes that the matron can hand them out." (Technical partner)

Moreover, some stakeholders discussed initiatives that pushed the approach a little further through pilot studies, allowing the provision of pills and injectables by community volunteers outside the health huts.

"Now, there are community volunteers who provide the pill and injectables. So then, they get it, FP has been transferred to the community level. Again I think that's a good thing. This is a step forward. We started the pill offer... community workers have now extended the range by offering injectables since April [2015] and since that month we had over a bundred women who are already using these methods." (NGO representative)

"There has been real progress. Today there are many initiatives that involve several stakeholders who are not specifically in the bealth sector. There are relays, matrons, bajenu gox that play a role in demand but also in referrals. There is really a demedicalization." (NGO representative)

"There is supply, there is awareness. It is not only medical personnel who provides. It is not only medical personnel who promotes awareness. That's it. It is not only the medical staff who builds awareness in associations and others ... there are leaders who are in the communities who we speak to. There are also bajenu gox who are there, who belp us a lot." (DMT member, Mbour)

As part of the development of FP at the community level, some actors, including government officials, reported the existence of the Policy on Community Health established in 2013, and the development of a National Strategic Plan for Community Health in 2014 (see literature review).

\section{Actions Cited by Female FP Users}

Data collected as part of the FGDs suggests that communities were informed of the preliminary training received by health workers at the community level for the provision of FP methods. But almost all women 
knew that they can now benefit from the provision of contraceptive methods by the matrons and CHWs in health huts.

"We group them and train them [matrons and CHWs], we show them the different methods, and tell them how they are used once in the villages." (FGD, Mbour)

"We trained CHWs and matrons in FP that is why they started to administer [methods]. Indeed, FP demand is so saturated that the midwives and doctors cannot do everything anymore." (FGD, Sandiara)

"At present, many women are limited to health huts, especially those living in remote areas ... But those who live far away visit the matron or the CHW so that they can provide the services. Everyone has it now." (FGD, Fissel).

"Training, is what was done for CHWs and matrons so that they can provide FP services" (FGD, Sindia).

\section{Successes and Achievements of Demedicalization}

According to FP stakeholders, success and achievements are mainly visible through the broadening of the range of methods in health huts, which was limited until recently to the pill, cycle beads and condoms. Indeed, almost all health huts, "97 percent" said an NGO representative, practice the IOP with trained matrons who are, in principle, regularly supervised. This same source stated: "In regards to the subcutaneous injections, it is 100 percent available in buts ... in 4 regions. But nationally it's 40 percent." A government official was on the same page: "Currently, there are more than 600 buts that offer injectables (Depo IM) and about 300 that offer Sayana ${ }^{\circledR}$ Press. So before they could not provide these methods, now they can, outside of the pill, cycle beads and condoms. So these are the methods that the matrons, CHWs can do. Counseling is also well done by these matrons there. I think it was successful in terms of demedicalization."

Taking into account the community component through this FP integration in health huts has helped to improve FP indicators. It also helped to make services much more accessible.

"For us, the success is the fact that matrons, when trained and supervised, they are able to offer the service, but in all dimensions. That is to say, not only do they receive women, they do initial counseling, they offer the method and especially they report back ... For me it is important that we have this critical mass of community health actors who are able to offer the service" (NGO representative).

"We trained community relays, CBHWs [community-based health worker] from a village. We trained them on the initial offer of the pill and they returned to their village. These relays have begun to advocate, do outreach visits, they built awareness, they began to offer the pill at community level. They were supervised and the HN was present. The HN bimself said that 'what the community relays offered in FP in 2 months, I haven't offered in 7 years'. Because, in the space of 2 months, they were able to enlist, recruit and offer almost 42 FP methods. And him for 7 years he has not even had 10 cases. So that means that it is a success" (NGO representative).

"The demedicalization has increased the number of FP users. The community level has a large share in the results we have today, and qualified personnel, on its own, could not have had that amount. And therefore, all this contributes to the increase in CPR. Although supply is still limited, at least it is close and women have more choices at health buts" (Technical partner).

In regards to information management, the establishment of a community FP file at certain infrastructures was a noted achievement. In addition, some respondents also pointed out the broadening of the range of stakeholders linked to provision: in addition to the intervention of matrons and CHWs, the community relays, whose focus is to integrate supply and create demand. "Relays, they create demand and they are suppliers at the same time. 
Providers they are in their rooms, they cannot create demand. Demand is created, they are referred to them. But the advantage at the community level, we create demand at we supply at the same time. It is much more beneficial for clients" (Government official).

Others reported that achievements include the reduction of the workload of qualified staff and the contribution to the reduction of unmet need.

"Because a woman, perhaps, she may need family planning. But she does not have time to go 5 kilometers, 10 kilometers away. So the provider is quite near. Or even, she does not even know where she has to go to get it. So this is a winning strategy, it is a strategy that makes it easy to reach people" (Government official).

Beyond reducing the cost of services for people, especially for rural women with the elimination of transportation costs, demedicalization also allows women to stay in the program because of the proximity.

"It reduces travel ... and it also reduces dropouts because when services are provided close to home, people are more likely to continue because sometimes people dropout because they do not have the means to continue, to go to appointments" (DMT member, Mbour).

"It reduces the cost of the care of women. Because a woman who had to pay for transportation to leave her village and go to another place, already it is a cost. For people who are in rural areas, who have incomes that are quite limited, the fact of reducing this cost is already a great success" (DMT member, Popenguine).

For female FP users, the success of demedicalization was highly visible and reflected primarily in:

- Proximity/geographic accessibility of the service

- Time saved

"Before we came to the hospital to queue, go to the market and back again to queue just to be able to do family planning. So, we lost a lot of time. The meal was not ready in time. But now, we go to the matron's. She quickly gets us the family planning" (FGD, Sindia).

- Confidentiality

"I see that demedicalization is good for society because there were constraints. Sometimes you want to go to the hospital but are afraid to meet an acquaintance. You know Senegalese society. You can go discreetly at night to the matron and tell her your problem quietly without anyone knowing it" (FGD, Mbour).

- Service availability

"They are more available. At any time, you can go see them as opposed to the health facilities where there are times to respect. Since some busbands do not agree with family planning, we can only rely on CHWs and matrons" (FGD, Thiadiaye).

- Improvement in rural women's lives

- Birth spacing

\section{Limitations of Demedicalization}

\section{For FP Stakeholders}

For FP stakeholders, the biggest weakness of demedicalization was the lack of motivation of community stakeholders. From their point of view, although these agents are committed to the principle of volunteerism, the increase of their workload due to their new skills could have led to accompanying measures, but these measures have not followed on a financial level, which does not make it easy to keep them in the system. 
"W hat did not work much is the financial side because I see that there are people who are very committed but not paid, the matrons, the bajenu gox ... they do not receive sufficient, substantial motivation to continue to work and I'm afraid that at they will fiz:le out because it takes a lot of effort and it's not always easy to get into the houses, to educate, sometimes you can be unvelcome, you can even suffer frustration" (Government official).

"So far, there is no financial incentive for these community agents, CHWs, matrons, even the relays, bajenu gox. We can talk about volunteering but in reality we think. we should support them on that score. So these are problems that are always related during the supervision that we do at the buts" (DMT member, Thiès).

Furthermore, many stakeholders bemoaned the lack of legislation to regulate the supply of services by community level stakeholders. Legislative aspects are even more of a problem because they also represent an obstacle to the provision of a wider range of contraceptives by pharmacists.

"Regulatory aspects, it is also a limit. We must be able to make it so that there is legislation on it. Until then, we can consider that this is a normal process. Because the legislator, the state always intervenes when the people have owned something." (Government official)

"There are some gray areas. The first regulations, the first pharmaceutical texts, the first medical texts had defined the stakeholders and their responsibilities. Even the pharmacist was not entitled to do injections, let alone the $C H W$. So if today we have to say $C H W$ that you can inject Sayana ${ }^{\circledR}$, you can inject Depo ${ }^{\circledR}$, the laws must follow. Although the decrees of the Ministry allow them to do so, the decrees do not protect them. Except that this $\mathrm{RH}$ law contains rubrics, items that can protect them so it simply needs to be applied and put into action, that means implementing legislation... a community relay is not new to Senegal. They just need to be accompanied in legal, regulatory and legislative aspects in order to be covered. We cannot have them doing activities while they are not supported legally” (NGO representative).

"The other aspect for demedicalization that went wrong is in relation to pharmacists. Injections were permitted for matrons while pharmacists who are Doctors of Pharmacy, took nursing courses, validated nursing, that is to say who can give injections and by whom this method cannot be given. They cannot administer because the law does not allow them to provide services. It's a bit paradoxical. And if you see the number of pharmacies and the distribution of pharmacies, we have a chance or a potential to increase the number of services that would provide family planning services, such as the pill, but injectables, even if they cannot insert IUDs or implants, but at least we allow them to do injectables" (Government official).

The lack of regular supervision was criticized by some stakeholders as potentially undermining the strategy in certain areas to the extent that these new skills require close monitoring, especially the supply of injectables, which remains a medical act.

"Where it works the least is in the districts that have appropriated the interventions and do regular monitoring. They supervise, they make advanced strategies. But I admit that that is the challenge, regular supervision by providers. Because we do not have the vocation to replace the Ministry, we only support the Ministry. So, it is health professionals who do the training, who are supposed to organize also, and track supervising" (NGO representative).

"These community agents, they are not health workers and they are given health tasks so there must be regular monitoring and regular supervision to avoid problems. That's missing a bit, because a single failure can ruin a lot" (DMT member, Thiès).

Furthermore, some stakeholders, especially at the central level, claimed to have noticed that the state is slow and it hesitates in the development of innovative experiences and their scaling up, which is one of the main obstacles to demedicalization. 
"We took our time with that. There have been delays in the implementation of innovative experiences. Since 2009 already, in meetings we talked about the introduction of injectables, and it was only introduced in 2015. (Technical partner).

"Since 2012, it was only in 2015 that they accepted the test phase. We lost 3 years... It's a bit about being slow to accept. Currently it is in the testing phase. ... but it is limited, we are expecting it to be conclusive so that we can scale up" (NGO representative).

Regarding management tools, although many stakeholders said that community health workers manage to do their activity reports correctly, they also recognized that it is because the latter are helped by relatives or community development agents (CDA), apart from a few exceptions (the case of CHWs who generally have a slightly higher level of education). They believe that the level of education, very low for the majority of these agents (particularly among matrons and relays), is problematic for the reporting of their activities. "The education level of relays is often very low. And often the collection tools are at a bigher level and often the relay does not have the ability to complete the collection tools" (NGO representative).

The management of side effects by community health workers appears to be an obstacle for demedicalization for some stakeholders. "It cannot work, these are people who can recognize the side effects, but do not have the technical training to handle them. So they have to do a referral" (DMT member, Mbour).

Also, the lack of systematic integration of health huts in the supply circuit was noted as a factor in the persistence of stock-outs at this level of the pyramid, hence the need to address this issue. "The current circuit is limited only to the health post level, not the health hut. So the huts sometimes experience stock-outs, there is some dysfunction." (NGO representative) Some also remarked upon the lack of health huts: "We have 2,900 buts in Senegal for 19,000 villages so that means there are only about a third of villages that are covered. So that means that there are many villages that have no buts" (Government official). Others pointed out that some women prefer to abandon the health hut in favor of the health post. According to them, there are two main reasons: either they need to hide, like many rural women, or there is a lack of trust.

"What has not worked very well firstly, is the use of health huts. Today if we had to calculate the offer with respect to health buts, compared to the offer in facilities such as health centers and posts, it really is not comparable. There is a feeling that the bealth buts are frequented for FP certainly but the rate remains low. You can see a but that, for example, only gets 2 or 3 clients in a month. But the explanation can be diverse and varied. (DMT member, Thiès).

"It's a trust issue, too. Because we all know that these are agents who are from the community, who are trained in the job somehow. And it is not always clear that they return to their community and can be trusted. These are also the realities that are out there" (DMT member, Thiès).

A source said the situation can also be related to inadequate services at the health hut. "Today we feel that the people, they have needs that go beyond just what the hut offers them. There is already a problem of availability or satisfaction of needs with the offer that exists in the but. So people may be forced to come to the health post in order to meet their needs. So it is with respect to the supply that is not always adequate in relation to the needs of the people." (DMT member, Thiès)

\section{For Female FP Users}

Allowing the community health workers to deliver FP did not reassure some women, despite all the benefits that this represents for others. In fact, their lack of confidence is evident and could be explained mainly by the low level of education of these agents.

"For me, what is reassuring is going to the health posts for family planning. This is what comforts me and that's what I do...go to health posts where they have studied and learned it. I have more faith in them than in the matrons and CHWs." (FGD, Mbour) 
In the opinion of some women, inadequate health huts at the community level also appears to be an obstacle to demedicalization, as this woman stated, "What is not working is that in many villages, there are no bealth buts; if we had built health huts in all villages in Senegal, it would work better. So they [women] are forced to go far to find health huts and often even the villagers around Mbour do it. So to make it work better, there need to be health buts everywhere" (FGD, Mbour).

\section{Opinions on LARC Provision by Community Health Workers}

Among FP stakeholders, opinions were divided on the idea of allowing CHWs and matrons to provide LARC. Some respondents thought that community workers are able to do so, and should be allowed to do so, but the majority thought we should tread carefully. The approval specifically concerned implants, for which insertion requires less medical technicality than an IUD, and the vaginal ring, which should soon be part of the range.

The stakeholders who were favorable to LARC provision by community health workers justified their position that this would boost the indicators, that new types of implants are easier to use, and that it is an experience already underway in other countries. All the same, they insisted that these agents be well supervised with respect to training, monitoring and supervision, and that they be motivated.

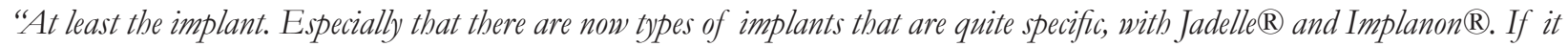
happens, it should easily be able to help. We talked about the vaginal ring. There are not any problems. So now, all these possibilities are there. So, there is a broad prospect for progress on these issues" (Government official).

"I do not know if they can do it with an IUD, but I think for the implant it can be done. And I think there are even countries where testing has already begun and it's going well. So we must go step by step. But we must learn good practices, there is no need to reinvent the wheel or to reflect on an issue for 10 years. You just have to watch what is happening otherwise, why it works, how it works, study and adapt. It's simply called benchmarking" (NGO representative).

"I never say no or I never say never ... the community actor, if trained, if monitored, I mean if properly supervised, if he has everything that he needs, this community actor is capable. Perhaps the theory will make the difference between the community actor... Currently, I'm pretty much pro-community, I know what the community actor is capable of, I know what he is not capable of. A community actor who used misoprostol, who manages misoprostol... misoprostol is not provided at the bealth center. If he is allowed to do that, I think the rest will not be that difficult" (SDT member, Thiadiaye).

However, those who opposed the idea of allowing community workers to provide LARC, mainly providers, put forward arguments related to the complexity of the act and the low skill level of these agents in this domain, to lack of equipment or to compliance with aseptic technique. They also cited simply jealousy.

"We are jealous of what we have learned over the years .... I am jealous. Yes, even for injections. I was cautious. ... Yet they are there, they provide, and what happened, the pill was bitter but still it passed. And still it goes. It takes how many years to train a midwife, it takes how many years for the midwife to learn how to do an intramuscular injection. That's why I'm jealous. And it takes how long to train a matron or a CHW, and we delegate... I will accept it, I will accept it little by little as the years pass, but initially it was not easy." (DMT member, Thiès)

'With implants, they can't. It's a little surgical and it is a bit difficult. Perhaps in the long run ... I do not know ... even midwives who have the training, they need additional training so that they can correctly insert the implants. The IUD, we do not even talk about it. There is also the need to sterilize equipment and they do not have the proper equipment to sterilize it." (DMT member, Mbour)

"I think that's what they can provide for now as to for long-term methods, not only is there the capability, there is also a need for equipment and I think. what has been delegated so far, it's good. We need to take a step back, to evaluate, to look at the advantages, 
disadvantages, etc. before thinking of delegating something else" (DMT member, Mbour).

For female FP users, almost all participants were opposed to LARC provision by community health workers. They justified this by citing the complexity of these methods, which require certain skills that the agents lack, and also the lack of technical equipment that is required.

"They can do Depo®, the pill. They cannot provide other methods because for these methods you need experienced and qualified health personnel. By mistake, it can happen that they place it where it is not supposed to be even the device [IUD]. That is why they cannot offer other methods at the moment so they should be limited to pill and injectables" (FGD, Mbour).

"Because there are instruments that matrons and CHWs do not have yet to provide other methods" (FGD, Sandiara).

"To each his specialty and skill level. We cannot do everything. To the matrons, what they master and can do and let the midwives also do what is part of their skill set to avoid any complications. Health is sensitive and critical. All that we do to and put on the buman body should be clear, safe and reassuring" (FGD, Popenguine).

\section{DECENTRALISATION}

\section{Actions Cited by FP Stakeholders}

Most FP stakeholders interviewed were aware of many actions in the context of decentralization. For example, the changes in the PNP to integrate the availability of FP products at the lowest level of the health system pyramid were highlighted. These provisions concretize the decentralization of FP provision. Outside of health facilities, advanced strategies (e.g. clinics and mobile teams) supporting women residing in remote areas also have contributed to this decentralization.

"You look throughout Senegal, there are tables and posters everywhere that show what FP services are, so it went all the way to the health buts, before it was just at the health posts, but now at the huts, we can access FP" (NGO Representative).

Also, not only is decision-making no longer centralized, as this government official pointed out: "This is no longer about scholars, an expert story, a story where everything is decided at the central level," but the trainings are done in situ. In this context, the Tutorat Plus initiative has provided vocational training to health care providers.

For most FP stakeholders, IPM was considered the most innovative action and the most decisive decentralizing of FP products through the consignment system (post-sale payment), which is not available for other essential medicines. This initiative, implemented in the interests of equity in response to problems of stock-outs, facilitated the distribution of these products, making them more easily available at all levels.

"Staff training is done at all levels. Because of this, FP services are now available at all levels of the health pyramid, even health buts. The supply of products at the SDPs [Service Delivery Point] has also been decentralized. Now, through the Push Model, there is an availability of products even in the most peripheral structures such as health huts" (FP stakeholder, Thiès).

Beyond the commodity, in terms of supply, information has also been decentralized through the involvement of community stakeholders and radio stations to facilitate informed choice for women. Additionally, some sources mentioned the strategy of itinerant midwives (IM), which also improves the provision of RH services in general and FP in particular (see literature review).

As part of the transfer of powers from the state to decentralized bodies, some local governments are 
beginning to invest in the construction of facilities, funding of FP, and recruitment of qualified personnel, particularly midwives.

"There have been cases in the Kaolack region, we were in one of the villages. The mayor, be is very young. He's barely 30 years old and he had good initiative. As soon as he arrived, through the town hall, he recruited a midwife who is there, and who is well integrated with the people" (NGO representative).

"Local elected officials, health committees have followed, including some mayors who recruited staff and provided funds for $\mathrm{RH}$ products" (NGO representative).

"There is also the involvement of mayors in the Dakar region, with the support of the Network Siggil Jigeen ... Yesterday there was an activity with all the mayors of Pikine, Guediawaye ... who are truly committed to increase their budget line to support FP" (Government official).

"Today we see mayors coming up with budget lines to buy FP products. I saw it in Pikine West, I saw it in Djidah Thiaroye Kao, I saw it in Guédiawaye, mayors who purchase products and make them available at their health posts. It is a commitment because at first all there was in the budget porffolio, in endowments, FP didn't get anything, so if today the mayors are really interested in buying products, in funding advanced strategies, in supporting NGOs in the implementation of these strategies, in what is called the days of the municipalities with FP that is already something" (NGO representative).

\section{Actions Cited by Female FP Users}

Female FP users mainly referred to the possibility, in recent years, of benefitting from the supply of services at all levels, and in both urban and rural areas.

"The government has allowed women to be able to do FP wherever they go, to facilitate their work, to avoid them having to travel" (FGD, Fissel).

"With decentralization, all women have access to FP. We no longer need to go to the big cities to access it" (FGD, Mbour).

"No matter how far away a village is, we make it so that there is a health hut so that everyone can access it [FP]" (FGD, Thiadiaye).

\section{Successes and Achievements of Decentralization}

\section{For FP Stakeholders}

From the perspective of the stakeholders, there have been many successes in both urban and rural areas. They included the increase in CPR, the improvement of geographical accessibility and the reduction of the cost of services. In rural areas, this is due, in particular, to the provision of services at the community level (health huts, neighborhoods and villages) and capacity building of service providers and local stakeholders. In addition, stakeholders stressed the availability and variety of contraceptive methods, which can offer more choice to women.

'Before it was said in supervision 'you must see if there are at least three modern contraceptive methods'. I think we no longer hear that. Now, we bave gone a little further than that. That, too, I think it is a success" (Government official).

Some sources also indicated that in the implementation of the NFPAP, moving away from the "top down" system previously applied, there has been real involvement at the community level and especially a sense of ownership of the goals by the regions. This involvement was reflected in the commitment of Head Regional 
Doctors (HRD) to revise upwards regional goals and to achieve them by developing a regional action plan, based on which facilities have been achieving their FP action plan since 2012.

"I think that as for the definition of objectives, it is the Head Regional Doctors who have given their objectives, nothing was imposed on them. Each according to his potential, according to the unmet needs of his region, the potential of women of reproductive age in the region, everyone has said this is what I can contribute to achieving that goal" (Government official).

"Although FP is based on free and informed choice, the various health officials took ownership of it and tried to make providers understand the importance of getting involved in the plan" (Government official).

Accountability at the community level seemed to be a reality for many, and they reported that it is visible through the exercise of new powers and the enthusiasm in the implementation of the NFPAP.

"We had the mid-term review of the plan and we felt some positive emulation amongst the medical regions, but it also happened in the districts... You must go to follow-up meetings of our plans at the regional level, you will realize that it is as if there was healthy competition between the districts and I think it is something extraordinary. People now vie with each other on good practices, on the recruitment of women, provision of services has improved, there is more FP adoption, we feel excitement around this plan and so I think it's something great" (Government official).

In addition, some stakeholders thought there is a better grip on FP policy at the operational level. "Iust go to the field to see how people have mastered the concepts, different strategic areas and in each area, what they are doing in terms of training, in terms of demand creation, in terms of social mobilization, in terms of radio emissions, in terms of availability, advocacy. I think that's a success" (Government official).

Some stakeholders pointed out that decentralization has helped make FP provision more equitable by increasing the number of SDPs and by adding value to the community level. As indicated by this health official at the local level in terms of the new powers of the agents: "they are not limited to routine, making bandages, distributing tablets."

\section{For Female FP Users}

According to female FP users, the greatest successes of decentralization lie in geographical access to FP, the reduction of the cost of service due to its proximity, and time savings. In addition, some women felt that service provision has become more equitable.

"Now it's closer and you walk, you go to the health center, they give you the method and you go home, it's more relaxing, you do not have to travel, to go back and forth" (FGD, Fissel).

"There are advantages for us because right now regardless of where you are, you can do it there. It's relaxing for women. Instead of paying for transportation to go far, you are doing in your location" (FGD, Thiadiaye).

"Now, there is no difference anymore between village women and urban women. Everyone is on the same footing because FP is everywhere, women now have time for themselves and to care for their husbands" (FGD, Mbour).

\section{Limitations of Decentralization}

While female FP users considered that everything went well with decentralization, FP stakeholders felt that some aspects could be improved.

Regarding the financing of FP, beyond the recognized efforts and measures taken on the budgetary side, some stakeholders noted a deficiency in the participation of local communities at the operational level. For example, 
they still depend too much on the state in the care of their staff. This can be explained by a lack of resources, but mainly by a lack of ownership of FP management.

"For decentralization, what I see is that we do not really feel the involvement of local authorities in the financing of FP while it is something they are able to do. Currently in the budget of these authorities, the state has planned something for the bealth sector, but in practice, it is something that one does not feel" (FP stakeholder, Thiès).

"As long as they do not have their own staff, as long as the staff continues to depend on the State of Senegal, there is something that will be a problem somewhere" (NGO representative).

"It is useless to decentralize if resources do not follow. Health is a transferred competency, it is decentralized so that means that local authorities must take responsibility for FP, but this has not been done yet... apart from recently I heard that there is a local authority in Dakar which has registered 10 million, but it does not move" (NGO representative).

Similarly, inadequate health facilities, including health huts, limit intervention coverage and are an obstacle to decentralization. Gaps were also observed in advanced strategies.

As for the information system, the skills needed to manage FP files caused problems. Also, recruitment of qualified personnel, especially midwives, is often contractual, which constitutes a difficulty for keeping them in programs.

"The only problem mentioned is that the committees are paying for years, after, if these people are recruited in the public service or have a contractual basis with the Ministry, we take them, we put them elsewhere, after, there is a problem. After, we must always start over, we look for otherpeople, we will then try to sign contracts with other midwives to resume training again. This is a shame" (DMT member, Popenguine).

The limited supply of methods at the health huts, including the lack of LARC, was seen by some stakeholders as a limit to decentralization.

"It means that, today, there are products, if the most remote populations want to use those products, they are still obliged to travel far. The offer is still limited" (DMT Member, Thiès).

According to some, irregularities are still observed in monitoring and supervision, which are requirements in the transfer of competence.

"Decentralization does not mean neglect. You cannot lean on the individual and then you forget him. What we have noticed, in general, is that the monitoring, supervision was not on point. There is still a gap" (DMT member, Thiès).

\section{OVERVIEW OF THE 3D APPROACH}

The study shows that respondents did not have a uniform perception of the implementation of the 3D approach. Opinions were divided on which " $\mathrm{D}$ " has shown the most progress over the last five years.

According to the majority of FP stakeholders at the central level, the actions taken as part of the "Democratization" produced the most visible results, because of achievements observed on the policy and program level, of advertising campaigns and of the involvement of other stakeholders: civil society, private sector (commercial and non-profit) and other ministries. From their perspective, "Demedicalization" and "Decentralization" were hampered by deficient sanitation infrastructure, shortages of qualified personnel, insufficient financial incentives, and the reluctance of some providers. 
On the other hand, for the majority of FP stakeholders at the operational level, it is "Decentralization" that resulted in the most progress. For them, its achievements were more tangible, through the services that become closer to the population, the capacity building of providers, and product availability. "Democratization" was seen as still limited, including access to services in some areas, and "Demedicalization" was perceived as limited by the lack of motivation of the community level staff.

"If there is work to do with this, it is with respect to democratization. Because today, it would be nice that people living in remote areas have the same opportunities as people living in urban areas. They are Senegalese citizens. This is democracy" (DMT member, Thiès).

"For Demedicalization what is lacking a bit are accompanying measures through regular supervision and proper motivation of community health workers. (FP stakeholder, Thiès).

Female FP users, for the most part, also felt that "Decentralization" is one of the most important achievements of recent years.

But beyond these differences of opinion, FP stakeholders and female FP users agreed that the 3Ds are complementary, interdependent, and that one cannot work without the other. In the words of this parliamentarian, "Democratization goes hand in hand with decentralization. To democratize, we need a decentralized system. Because it gives access to all levels of the health pyramid. So we cannot democratize without this decentralized support. And it's because it does exist that we have the opportunity to demedicalize. Mathematicians talk about transitivity."

In addition, the 3D approach was seen as a good approach because of, among others things, the multi-sectoral dimensions it integrates. This is an innovative approach that deserves to be better systematized and popularized for proper stakeholder ownership and, as stated by a technical partner, "This is an innovative approach to the point that some countries in the sub-region such as Togo have begun to adopt it." So this approach must be more democratized.

"It's a very good approach that we need to systematize, really. Really really systematize, better teach people, better popularize at central level, at regional level, at the departmental level, at all levels. And so that people understand what it is about, that people commit to the guidelines towards the proper application of this approach" (NGO representative).

"This is a good approach, it's a good strategy, that requires everyone be really, really informed, up to date, aware of everything that there is in this 3D approach, because I am sure there are many people who have lots of ideas about how to carry out this 3D approach" (NGO representative).

In the opinion of the majority of people interviewed, especially at the regional level, the communication around this concept is all the more important, since they see it as new on the conceptual level, if not operationally. This study was an opportunity for them to realize that this is an approach that is applied daily as part of their activities, without even realizing it.

"Ultimately, the 3D approach is something we do every day without even knowing it. So this study is really a good initiative. You just have to popularize [the approach] so that interventions are better structured and that stakeholders can have a framework. for what they do" (FP stakeholder, Thiès).

"There, it becomes much more concrete after this discussion, but it was something very abstract. Maybe people are already doing it, but they do not know that it fits into a certain approach. And I think. communication on this level, for the persons involved, key resource people, it would be a very good thing. Other ideas can go out, that can feed it" (Government official). 
'I think. it's a great study because it even allows us to look at things again, to better get involved, to better measure the impact of what we do because it was not obvious for $3 D$... it is something we really do, but it allows us to systematize and classify each activity we lead because these are things we do, but sincerely I am fascinated by this approach ... . at first, I was a bit skeptical, I thought 'what am I going to say about this approach that I don't understand', but after I thought, 'well, that's really what we do' but we lead activities without being able to put them into categories and it is an excellent approach" (DMT member, Mbour).

Actors, both at the central and regional levels, were so attracted by the 3D approach and its results, that they unanimously thought that it should be extended to serve as a guideline in developing the next NFPAP. However, they emphasized as a prerequisite the assessment of the current plan, to see its impact.

"We saw the results; I think we do not change a winning strategy" (DMT member, Thiès).

"I think it's something that we can renew for the next plan. But first, we need to asses it. But this is a very good approach" (Technical partner).

Regarding the implementation of the 3D approach across the country, most stakeholders thought it has been better developed in the regions that benefit from the presence of many partners (e.g. Dakar, Saint-Louis, Thiès). For regions having experienced obstacles, apart from the absence or scarcity of partners, other factors were mentioned, such as sociocultural obstacles, refusal of service providers to practice in these areas, or lack of dynamism and ownership of the program by HRD.

\section{PERCEIVED EFFECTS OF THE 3D APPROACH}

According to FP stakeholders, several effects can be attributed to the implementation of the 3D approach including: availability of FP services to the people, increased use of health facilities, increase in CPR, capacity building of community stakeholders, reduction of risky pregnancies, better acceptance/adoption of FP, product availability, and lower maternal and child mortality.

"For me the improvement of contraceptive prevalence that we talked about, it is in relation to that. This is in relation to all the efforts that have been made to improve access to services, to improve access to medicine, slightly reduce the socio-cultural barriers. So I think that this approach has played a role, even if people can practice without realizing it" (NGO representative).

"This approach has significantly contributed to increasing the contraceptive prevalence rate. However, it will take a more rigorous evaluation to assess its real impact. From the demand side, this approach has removed certain socio-cultural barriers. There are more religious leaders who are now favorable to FP" (NGO representative).

"The indicators speak for themselves. So we really see what the impact of decentralization is. Because the indicators are now really up in different areas, so that you may have had 12 percent at the central level, 16 percent and now 20 percent now. And we see that this is not Dakar makes this great leap ... but there really is a performance in regions considered difficult where we did not expect it. They are still things to be recognized, they should be emphasized" (NGO representative).

For even better results, these stakeholders advocated the scaling up of task shifting, strengthening advanced and mobile strategies, involvement of community leaders, and informing stakeholders of the approach.

"There needs to be an upgrade or an orientation for people with information about the approach. That tool must be more systematically used in the implementation of interventions" (NGO representative).

"There is better adoption by men, a better adoption by women and a better adoption by religious leaders. I think that Senegal is now demonstrating that with proper involvement of all stakeholders the CPR can be doubled in 3 years" (Government official). 
As one stakeholder said, "It is possible to make very significant leaps if all policies are united." But some stakeholders, especially at the central level, drew attention to the need to strengthen coordination and to the multi-sectoral dimension that did not seem completely efficient to them.

"For these results to be better, everyone needs to feel affected. And therefore, there will be better resources (multi-sectoral dimension). If the multi-sectoral dimension works, we will have better impact" (Technical partner).

Female FP users reported that they now enjoy the effects of FP use, such as birth spacing, the decline in maternal mortality, and keeping girls in school. This is because, according to them, the results of actions undertaken in the context of $3 \mathrm{D}$, such as geographical and financial access to contraceptive methods, improvement of public FP knowledge, product availability, and the involvement of husbands in the decision of couples to practice family planning.

"Over these five years, we see that FP is much more decentralized, balf the population has felt the impact of FP and this was not the case before because there were places where FP did not exist. But during these 5 years everyone has had access to it" (FGD, Mbour).

"It is also important the way we tried to conduct awareness campaigns on TV about family planning. If there were 100 who were dying because of it, now there are only 10 who die. This is very important" (FGD, Ndayane).

For the greatest impact, women suggested strengthening communication and avoiding product shortages.

\section{SUSTAINABILITY OF THE 3D APPROACH}

In the opinion of many FP stakeholders, the sustainability of the 3D approach requires good awareness for a better understanding in order to move beyond the conceptual level. It also requires greater involvement and ownership by the districts, communities, other sectors of intervention, especially local communities and the state. Everyone must play his full role in setting up sustainability strategies, including motivation of community actors and product security, because most of the needs are currently covered by partners.

"There are still many things that are left in the hands of donors or of implementing partners. In the vision of the Ministry of Health and of the DRH, we must be able to learn lessons and we must see how to sustain this because donors and implementing partners will not always be there. And that the idea is that if something still works, we must continue it but through our own means. So that, it must be very, very, very maturely thought on" (NGO representative).

'That's product security, so that there are no shortages and that from the NGOs starting point, that continues. That the state finds ways to sustain. Many NGOs have passed through. There are so many NGOs that have come through Senegal - if they leave, it's back to square one. We must raise awareness. We must tell them that this is for you not for them and little by little the state guides people towards independence" (NGO representative).

For the most part, female FP users believed that the sustainability of the 3D approach is subject to greater awareness, especially among men, decision-makers and mothers-in-law, to increased product availability, and to ongoing training of community actors.

'It's the men we need to talk to so that they support women ... The mothers-in-law, I think it's also important to go into homes and educate them as they do with men. They often throw stones at us. They do not help us. They do not agree because they say that in their time, they did not do family planning. (FGD, Ndayane). 


\section{Discussion}

The results of this study show that the 3D approach is not well-known by FP stakeholders as a concept, even if they in fact regularly practice it operationally. Its implementation is in a context marked by a willingness of the highest officials to boost FP and to reduce unmet need. Changes at the institutional, political and organizational levels suggest that the approach has strong promise for achieving Senegalese development goals. However, its inclusion in the next FP action plan requires consideration of some of the challenges for each " $\mathrm{D}$ ":

\section{DEMOCRATIZATION}

- The difficult economic situation of the majority of the population, especially in rural areas, led to the development of free services. However, health facilities have financial resources requirements and are obliged to recover costs from clients. This leads to blockages for democratization.

- Legal and regulatory provisions constitute barriers to private sector involvement, including pharmacies and private practices, and should be revised in order to open opportunities for service expansion. However, to ensure market stability and equity of access, it will be necessary to address the issue of subsidies (or not) of products in the for-profit private sector.

- Placing the FP debate into the public square has certainly facilitated discussion for couples and in the community, but issues still exist. For example, the NFPAP targets women in union, and although there is a strategic plan for youth and adolescent RH, FP for young single people is not explicitly taken into account. For religious and cultural reasons, early sexual activity is a sensitive topic. However, it is urgent to implement specific interventions for all young people, who represent a significant part of the population.

- The many cases of unwanted pregnancies, illegal abortions and the major physical and mental consequences of these, the abandonment of children or infanticide are all indications of unmet need. Stakeholders in the FP field were questioned about measures to be implemented to ensure access and that FP users voluntarily stay in the program.

- The contribution of FP to economic and social development is well established. Similarly, there is consensus about the importance of the effective involvement of other governmental structures (including Ministries of Education; of Women, Family and Children; of Youth; of Economy and Finance; and of Communication) for the promotion of democratization. Discussion now should be directed towards finding solutions for the integration of the contribution of each sector so that multisectorality is not just a slogan, but a reality.

\section{DEMEDICALIZATION}

- The integration of health huts in the health pyramid appears to be a priority in a context where community staff motivation issues are acute.

- In addition, although progress has been made in the use of community health workers for service provision, the study showed that their credibility is not guaranteed either with FP stakeholders or with female FP users. Efforts must be intensified to ensure the quality of services provided at that level, so as not to give fodder to detractors and undermine the gains. This ranges from training to monitoring/ supervision to motivation.

- Legal and regulatory frameworks need to be strengthened to enable supervised involvement of community health workers. 


\section{DECENTRALIZATION}

- The lack of health infrastructure and qualified personnel require the development of alternatives such as improved health huts. This could help to advance decentralization in a situation where cultural constraints are still real.

- For program sustainability, the insufficiency of Senegal's contribution deserves particular attention to avoid the continued financing of FP by TFP. Indeed, it seems difficult to talk about sustainability when product availability is linked to external financing. Beyond political will and the existence of a dedicated budget line, substantial and effective strengthening of financial resources would contribute to greater support from the national party for the availability of contraceptives. Advocacy for increased funding of FP by state and local authorities, which is beginning to show results, must be supported. 


\section{Good Practices to be Explored}

This study highlights the use of several good practices, some of which are recognized as High Impact Practices (HIP).

\section{Democratization}

- Advanced strategies (mobile teams and other models described in the literature review) to reach the most remote populations.

- The involvement of men and religious leaders, who represent crucial participants in communicative actions; some are FP champions. Interesting results have been observed in terms of their role in FP adoption by people.

- The creation of a favorable political and legal environment by the state, as well as financial commitment from the state.

\section{Demedicalization}

- The use of community health workers in the provision of a wider range of methods, which facilitates rural women's access to FP, especially those in the most remote zones.

\section{Decentralization}

- The development of an efficient provision system with IPM, which has led to a considerable decrease in stock-outs.

- Advocacy for increased financing of FP services and products by the state and local authorities.

- Reinforcing health posts staff with midwives in some regions.

- The implementation of improved health huts. 


\section{Recommendations}

Recommendations are presented below, grouped by audience.

\section{STATE/MHSA}

- Create more health facilities in order to bring services closer to the people - every $5 \mathrm{~km}$, less if possible.

- Improve the availability and distribution of qualified health personnel.

- Guarantee the training of qualified personnel, as well as community personnel.

- Implement systematic and regular monitoring at all levels.

- Increase the dedicated FP budget line and effectively commit funds as rapidly as possible.

- Document and review the legal and regulatory frameworks that hinder service provision by the private sector and community health workers.

- Implement mechanisms aimed at reinforcing community staff motivation.

- Implement measures for compliance with the memorandum on prices.

- Ensure that the PNP are available and in accordance with what is happening in the field.

- Ensure leadership for the effective implementation of multi-sectoral dimensions of FP/RH service provision.

- Provide leadership to inventory and document, including the cost component, good practices resulting from interventions implemented. Widely share the results to allow their use in the implementation of programs and projects in Senegal and elsewhere.

- Facilitate the scaling up of interventions recognized as good practices.

- Popularize the 3D approach for better ownership and application.

- Clearly specify how the 3D approach is articulated in the next NFPAP.

\section{FP STAKEHOLDERS/TECHNICAL PARTNERS}

- Assume more ownership of the 3D approach and link it to interventions.

- Strengthen training support for qualified personnel as well as community personnel.

- Strengthen advocacy for increased financing by state and local authorities for FP.

- Strengthen involvement of communities, especially men and religious leaders, in communication actions.

- Assess and document in detail successful and unsuccessful interventions, including the cost component, in order to learn lessons and to share them with other stakeholders, for the benefit of all.

- Assess and document good practices, including the cost component, in order to allow replication, scaling up and sharing.

- Collaborate to scale up good practices.

\section{FINANCIAL PARTNERS}

- Guarantee the availability of products for the range of methods available in Senegal.

- Support the implementation of FP/RH research and intervention programs contributing to the achievement of development goals in Senegal and globally, such as Sustainable Development Goals (SDGs). 


\section{Study Limitations}

The main limitations of this study are the lack of responses from certain FP stakeholders whose point of view could not be taken into account and the difficulty in locating and obtaining documentation about the 3D approach and interventions referring to it. These limitations mean the descriptions of stakeholders and 3D-related interventions are somewhat incomplete. This study was not designed to determine whether the approach has achieved goals that were set for it in advance, as such goals do not exist, but rather to document what has been accomplished. Finally, since the study was limited to the areas of Dakar and Thiès, it is possible that there are specificities of other regions that did not emerge here. 


\section{Conclusion}

Officially launched in 2012, the 2012-2015 NFPAP has enabled Senegal to make significant progress in the area of FP. The 3D approach, on which the NFPAP was based, was not a well-known concept among stakeholders, but was recognized after explanation. It affects the political aspects as well as operational aspects of FP.

Democratization, which encompasses the involvement of various ministries and other stakeholders such as parliamentarians, civil society, the private sector, local elected officials, religious and community leaders, was deemed essential. It has allowed, among others things, for the improvement of knowledge and perceptions of FP among the people, for the harmonization of contraceptive prices, the expansion of services and an increase in women's leadership.

Demedicalization, through task shifting and community-based distribution, has helped broaden the skills of community health workers and bring services closer to the people.

Decentralization, which fosters ownership and accountability at all levels, has allowed access to a wider range of modern family planning methods, including: the scaling up of IOP and IOI; increase of SDPs, including the rehabilitation of health huts; and the introduction of LARCs at health posts. Decentralization has also helped to ensure the availability of products at the most remote locations.

Thus, 3D-related achievements have contributed to the marked improvement of family planning indicators. DHS-C data and the results of the mid-term review of NFPAP in February 2015 show successive CPR leaps for the past three years, rising from 12 percent in 2012 to 20 percent. Efforts must be pursued to achieve the goal of 27 percent by 2015 .

Finally, the sustainability of the 3D approach necessarily involves better knowledge and ownership of the approach by stakeholders, a real application of the multi-sectoral dimension, a review of legal and regulatory frameworks, and the involvement of state and local authorities in FP funding. Inclusion of the approach and its articulation from the very beginning of the development of the next NFPAP are essential to more quickly boost FP in order to improve the health of the population and to reduce maternal, newborn and child mortality. 


\section{References}

Agence Nationale de la Statistique et de la Démographie (ANSD) [Sénégal], et ICF International. 2012. Enquête Démographique et de Santé à Indicateurs Multiples au Sénégal (EDS-MICS) 2010-2011. Calverton, Maryland, USA: ANSD et ICF International.

Agence Nationale de la Statistique et de la Démographie (ANSD) [Sénégal], et ICF International. 2013. Enquête Démographique et de Santé Continue (EDS-Continue 2012-2013). Calverton, Maryland, USA: ANSD et ICF International.

Agence Nationale de la Statistique et de la Démographie (ANSD) [Sénégal], et ICF International. 2015. Sénégal : Enquête Démographique et de Santé Continue (EDS-Continue 2014). Rockville, Maryland, USA : ANSD et ICF International.

Cabinet Sen Ingénierie Consult. Décembre 2014. Evaluation à mi-parcours de la campagne de communication sur la Planification Familiale 2013-2014. Rapport final. Dakar : Ministère de la Santé et de l'Action Sociale.

Cellule de Santé Communautaire et Ministère de la Santé et de l'Action Sociale. 2014. Plan National Stratégique Santé communautaire 2014-2018. République du Sénégal.

Cellule de Santé Communautaire et Ministère de la Santé et de l'Action Sociale. 2015. Document cadre de la stratégie des sages-femmes itinérantes. Dakar : Ministère de la Santé et de l'Action Sociale.

Daff BM, Seck C, Belkhayat H, Sutton P. 2014. Le système de distribution en « Push » des contraceptifs mis en place au Sénégal réduit les ruptures de stock et améliore la qualité des services de planning familial. Global Health Sci Pact. 2014; 2(2):245-252. Disponible sur http://dx.doi.org/10.9745/ GHSP-D-13-00171

Direction de la Santé de la Reproduction et de la Survie de l'Enfant. 2012. Rapport de la revue du Programme Bajenu Gox. Dakar : DSRSE.

Direction de la Santé de la Reproduction et de la Survie de l'Enfant (DSRSE) et Ministère de la Santé et de l'Action Sociale (MSAS). 2013. Plan opérationnel de plaidoyer sur la planification familiale 2013-2015. Dakar : DSRSE.

Division de la Planification Familiale, Direction de la Santé de la Reproduction et de la Survie de l'Enfant et Ministère de la Santé et de l'Action Sociale. 2013. Plan d'introduction et d'évaluation de Sayana ${ }^{\circledR}$ Press au Sénégal. Dakar : DSRSE.

Division de la Santé de la Reproduction (DSR) et Ministère de la Santé et de l'Action Sociale (MSAS). 2011.

Plan Stratégique de la Santé de la Reproduction du Sénégal 2012-2015. Dakar : MSAS.

Division de la Santé de la Reproduction (DSR) et Ministère de la Santé et de l'Action Sociale (MSAS). 2012.

Plan d'Action National de Planification Familiale 2012-2015. République du Sénégal. Dakar : MSAS.

Division de la Santé de la Reproduction des Adolescent(e)s/Jeunes, Direction de la Santé de la Reproduction et de la Survie de l'Enfant (DSRSE) et Ministère de la Santé et de l'Action Sociale et (MSAS). 2014. Plan Stratégique de Santé Sexuelle et de Reproduction des Adolescent(s)/Jeunes au Sénégal 2014-2018. Dakar : MSAS. 
Dubent L, Mbow FB, Diop N, Ndiaye F, Daff BM \& Mané B. 2015. "Evaluation de la mise en oeuvre et des réalisations de l'Approche 3D au sein du Plan d'Action National de Planification Familiale (PANPF) au Sénégal. Partie 1: Revue de la littérature,” Rapport. Dakar, Sénégal: Population Council, Le Projet Evidence.

Gouvernement du Sénégal. 2005. Loi no 2005-18 du 5 août 2005 relative à la santé de la reproduction. Dakar: Gouvernement du Sénégal.

High-Impact Practices in Family Planning (HIP). 2014. Financing commodities and services: mobilizing resources to sustain current and future family planning demand. Washington, DC: USAID. Disponible sur: https://www.fphighimpactpractices.org/sites/fphips/files/hip_financing_fre.pdf (Consulté le 28/10/15).

Mané B, Diop N, Termini N, Ramarao S, Clark H. 2012. Anneau vaginal à la progestérone. Cartographie pays : Sénégal. Dakar: Population Council.

Mbow FB, Ningue EAB, Diop N, Mané B, Ngouana R. 2015a. "La délégation des tâches dans le domaine de la planification familiale au niveau communautaire dans les pays du Partenariat de Ouagadougou: Expériences et leçons apprises pour une mise en œuvre effective - Présentation par pays". Dakar: Population Council.

Mbow FB, Ningue EAB, Diop N, Mané B, Ngouana R. 2015b. "La délégation des tâches dans le domaine de la planification familiale au niveau communautaire dans les pays du Partenariat de Ouagadougou: Expériences et leçons apprises pour une mise en œuvre effective - Rapport de synthèse”. Dakar: Population Council.

Ministère de la Santé et de l'Action Sociale (MSAS). 2014. Lettre circulaire N008938/MSAS/DGS/CSC du 11 aout 2014 portant extension de l'offre initiale de contraceptifs injectables intramusculaires et souscutanés au niveau communautaire.

Ministère de la Santé et de la Prévention. 2010. Lettre circulaire Nº07607/MSP/DSR du 26 juillet 2010 fixant les prix de cession des produits contraceptifs.

Ndiaye S, et Ayad M. 2006. Enquête Démographique et de Santé au Sénégal 2005. Calverton, Maryland, USA: Centre de Recherche pour le Développement Humain [Sénégal] et ORC Macro.

Partenariat de Ouagadougou. 2011. La planification familiale : l'Afrique de l'ouest francophone en mouvement. Un appel à l'action.

PATH. Janvier 2015. Recherche sur l'auto-injection de Sayana ${ }^{\circledR}$ Press. Seattle : PATH.

Pharmacie Nationale d'Approvisionnement (PNA). Décembre 2014. Modèle de Distribution Concertée (MoDisc) « jegesi naa ». Note Conceptuelle. Dakar : République du Sénégal.

Projet Initiative Sénégalaise de Santé Urbaine (ISSU). 2014a. Rapport de la capitalisation des approches du «paquet porteur» des interventions du projet ISSU. Dakar : IntraHealth International.

Réseau Siggil Jigeen. 2015a. «Le gain rapide. Cas de la commune de Pikine Djidah Thiaroye Kao ». Dakar. Réseau Siggil Jigeen. 2015b. Plaidoyer de budget avec le maire de la commune de Mbao. Dakar.

Réseau Siggil Jigeen. 2015c. Rapport trimestriel d’Advance Family Planning- Février Mars Avril 2015. Dakar.

Sidze EM, Lardoux S, Speizer IS, Faye CM, Mutua MM, Badji F. 2015. Accès et recours des jeunes femmes à la contraception: rôle des restrictions imposées par les prestataires en milieu urbain au Sénégal. Per- 
spectives Internationales sur la Santé Sexuelle et Génésique. Numéro spécial de 2015, pp. 20-28. Doi: 10.1363/ FR02015.

The RESPOND Project. 2014. Reality Check experiences: Use of a program planning and advocacy tool for family planning initiatives. RESPOND Project Brief No. 22. July. New York: EngenderHealth (The RESPOND Project).

USAID-Sénégal. 2011. Expérience acquise de Programme de Santé Communautaire ChildFund/USAIDSénégal. Évaluation Finale - Programme de Santé Communautaire du Sénégal/ChildFund 2006-2011. Dakar: USAID Sénégal.

\section{Websites Visited}

Bureau de l'OMS au Sénégal. Bulletin d'information du Bureau de l'OMS au Sénégal no108, aout 2013.

Disponible sur http://www.afro.who.int/fr/senegal/press-materials/item $/ 5842$ - acc $\% \mathrm{C} 3 \% \mathrm{~A} 91 \% \mathrm{C} 3 \% \mathrm{~A}$ 9ration-de-la-r $\% \mathrm{C} 3 \% \mathrm{~A} 9$ alisation-des-omd-relatifs- $\% \mathrm{C} 3 \% \mathrm{~A} 0-\mathrm{la}-\mathrm{r} \% \mathrm{C} 3 \% \mathrm{~A} 9$ duction-de-la-mortalit\%C3\%A9-maternelle-et-n\%C3\%A9onatale.html. Consulté le 14/10/2015.

Family Planning High Impact Practices. Pratiques à Haut Impact dans la Planification Familiale. 2014.

Disponible sur https://www.fphighimpactpractices.org/sites/fphips/files/hip_list_fre.pdf. Consulté le $23 / 10 / 2015$.

Partners in Population and Development Africa Regional Office. Le dividende démographique et le développement. Disponible sur http://www.ppdafrica.org/docs/policy/demo-f.pdf. Consulté le 22/10/2015.

\section{Presentations}

Daff Bocar Mamadou. Planification familiale au Sénégal. Amélioration de l'accès par les 3D. Conférence "Population, développement et planification familiale en Afrique de l'ouest francophone : l'urgence d'agir", Février 2011, Ouagadougou.

Marie Stopes International. La Franchise Sociale MSI au Sénégal, Février 2015.

Marie Stopes international. Les équipes mobiles pour atteindre les populations défavorisées, Saint Louis, Avril 2015.

Marie Stopes International. Mobiliser les Jeunes pour un comportement sain et responsable, Mai 2014.

Projet Initiative Sénégalaise de Santé Urbaine (ISSU). 2014 b. « Synthèse des résultats de l'enquête à mi- parcours ». DSRSE, Atelier de restitution des résultats de l'enquête à mi-parcours, de l'évaluation de l'ISBC et du processus de capitalisation du « Paquet Porteur » du projet ISSU, Dakar, 24 juin 2014. 
The Evidence Project

Population Council

4301 Connecticut Avenue, NW, Suite 280

Washington, DC 20008 USA

tel +12022379400

evidenceproject.popcouncil.org 